\title{
Hydrogen alleviates mitochondrial dysfunction and organ damage via autophagy-mediated NLRP3 inflammasome inactivation in sepsis
}

\author{
HONGGUANG CHEN ${ }^{1,2^{*}}$, XING MAO $^{1,2^{*}}$, XIAOYIN MENG ${ }^{3}$, YUAN LI $^{4}$, JINGCHENG FENG $^{1,2}$, \\ LINLIN ZHANG ${ }^{1,2}$, YANG ZHANG ${ }^{5}$, YAOQI WANG ${ }^{1,2}$, YONGHAO YU $^{1,2}$ and KELIANG XIE ${ }^{1,2}$ \\ ${ }^{1}$ Department of Anesthesiology, Tianjin Medical University General Hospital; ${ }^{2}$ Tianjin Research Institute of Anesthesiology, \\ Tianjin 300052; ${ }^{3}$ Department of Gynecology and Obstetrics, Tianjin Hospital, Tianjin 300211; \\ ${ }^{4}$ Department of Anesthesiology, Tianjin Medical University Cancer Institute and Hospital, \\ National Clinical Research Center for Cancer, Tianjin 300060; ${ }^{5}$ Department of Anesthesiology, \\ Tianjin Fourth Center Hospital, Tianjin 300140, P.R. China
}

Received March 10, 2019; Accepted July 26, 2019

DOI: $10.3892 /$ ijmm.2019.4311

\begin{abstract}
Sepsis is a highly heterogeneous syndrome that is caused by a dysregulated host response to infection. The disproportionate inflammatory response to invasive infection is a triggering event inducing sepsis. The activation of inflammasomes in sepsis can amplify inflammatory responses. It has been reported that damaged mitochondria contribute to NACHT, LRR and PYD domains-containing protein 3 (NLRP3) inflammasome-related sepsis. Our previous study revealed that hydrogen $\left(\mathrm{H}_{2}\right)$ exerts anti-inflammatory effects
\end{abstract}

Correspondence to: Dr Yonghao Yu or Dr Keliang Xie, Department of Anesthesiology, Tianjin Medical University General Hospital, 154 Anshan Road, Tianjin 300052, P.R China

E-mail:yyu@tmu.edu.cn

E-mail: mzk2011@163.com

*Contributed equally

Abbreviations: 3-MA, 3-methyladenine; ASC, apoptosis-associated speck-like protein containing a CARD; ATP, adenosine triphosphate; BALF, bronchoalveolar lavage fluid; BCA, bicinchoninic acid; CLP, cecal ligation and puncture; ELISA, enzyme-linked immunosorbent assay; $\mathrm{H}_{2}$, hydrogen; IL, interleukin; JC-1, 5,5',6,6'-tetrachloro-1,1',3,3'-tetraethyl benzimidalyl carbocyanine iodide; LPS, lipopolysaccharide; LC3, microtubule-associated protein 1 light chain 3; MMP, mitochondrial membrane potential; MPO, myeloperoxidase; mtDNA, mitochondrial DNA; NLRP3, NACHT, LRR and PYD domains-containing protein 3; PAM, primary alveolar macrophage; PINK1, PTEN-induced putative kinase 1; Rap, rapamycin; RCR, respiratory control ratio; ROS, reactive oxygen species; SDS-PAGE, sodium dodecyl sulfate-polyacrylamide gel electrophoresis; TNF, tumor necrosis factor; VDAC, voltage-dependent anion channel

Key words: sepsis, inflammation, inflammasome, autophagy, hydrogen in sepsis but the detailed mechanism remains to be elucidated. In the present study, septic mice induced by cecal ligation and puncture (CLP) and macrophages induced by lipopolysaccharide (LPS) were used as models of sepsis in vivo and in vitro, respectively. An inducer and inhibitor of autophagy and the NLRP3 inflammasome were administered to investigate the detailed mechanism of action of $\mathrm{H}_{2}$ treatment in sepsis. The results demonstrated that LPS and ATP led to NLRP3 inflammasome pathway activation, excessive cytokine release, mitochondrial dysfunction and the activation of autophagy. CLP induced organ injury and NLRP3 pathway activation. $\mathrm{H}_{2}$ treatment ameliorated vital organ damage, the inflammatory response, mitochondrial dysfunction and NLRP3 pathway activation, and promoted autophagy in macrophages induced by LPS and in CLP mice. However, the inhibitor of autophagy and the inducer of NLRP3 reversed the protective effect of $\mathrm{H}_{2}$ against organ damage, the inflammatory response and mitochondrial dysfunction in vivo and in vitro. Collectively, the results demonstrated that $\mathrm{H}_{2}$ alleviated mitochondrial dysfunction and cytokine release via autophagy-mediated NLRP3 inflammasome inactivation.

\section{Introduction}

Sepsis is a heterogeneous syndrome that is caused by a dysregulated host response to infection (1). It was reported that there were 391,544 cases of severe sepsis and the crude case mortality rate for severe sepsis was $37.7 \%$ in 2003 (2). Due to population aging, individuals live longer with chronic diseases; furthermore, due to the spread of antibiotic-resistant organisms and the broader use of immunosuppressive and chemotherapeutic agents, the number of cases of sepsis is increasing $(3,4)$. Sepsis imposes a substantial global burden in terms of morbidity and mortality, and there is currently no satisfactory therapeutic method, as sepsis is characterized by a complicated pathophysiological process leading from infection, sepsis and severe sepsis to septic shock. The disproportionate inflammatory response to invasive infection is a triggering event, which is 
closely associated with sustained excessive inflammation and immune suppression and leads to a failure in restoring normal homeostasis. Pro-inflammatory cytokines, such as tumor necrosis factor (TNF), interleukin (IL)-1 $\beta$, IL-12 and IL-18, serve a vital role in the pathogenesis of sepsis, and the inhibition of these cytokines is associated with reduced bacteremia and systemic inflammatory response (5).

Inflammasomes are cytosolic multimeric protein complexes that facilitate the maturation and secretion primarily of IL-1 $\beta$ and IL-18 against invading pathogens or danger signals in immune cells (6). The activation of inflammasomes during sepsis can amplify inflammatory responses. The nucleotide-binding domain and leucine-rich repeat pyrin 3 domain (NLRP3), one of the most well-characterized sensor proteins and inflammasomes, initiates innate immune defense responses in response to different danger or cell stress signals triggered by exogenous and endogenous pathogens, reactive oxygen species (ROS), mitochondrial (mt) DNA and extracellular ATP (7). Activated NLRP3 recruits the adaptor protein apoptosis-associated speck-like protein containing a CARD (ASC) and procaspase-1 to form a complex, resulting in the autocatalytic activation of caspase-1, which cleaves the pro-forms of inflammatory cytokines IL-1 $\beta$ and IL-18 into their mature forms which act as potent cytokines secreted from the cell to become involved in the cell immune response. Notably, the NLRP3 inflammasome has been reported to be closely associated with the innate immune defense response in sepsis (7) and other infectious diseases in animal models (8-10), indicating that the lack of NLRP3 contributes to the low production of inflammatory cytokines, reduces susceptibility to inflammation and facilitates the recovery of inflammatory response and organ damage. Mice with NLRP3-, ASC- or caspase-1 knockdown exhibit a major defect in the maturation of IL-1 $\beta$ and IL-18 in response to lipopolysaccharide (LPS) and ATP stimulation, or are resistant to LPS-induced lethality $(11,12)$. In vitro, macrophages serve an important role in mediating the inflammatory response during infection. Bacterial LPS and/or ATP may activate NLRP3 and promote the maturation of IL-1 $\beta$ and IL-18 in macrophages $(13,14)$.

Autophagy serves different roles in terms of protection and impairment in a variety of models, however, its role in human diseases has not been clearly defined. Autophagy is a dynamic process from autophagosomal induction and formation to autophagosome-lysosome fusion, which enables the regeneration of damaged proteins and organelles, including mitochondria (15). A previous study provided evidence that damaged mitochondria contribute to NLRP3 inflammasome-related sepsis (16). Mitophagy, a primary mitochondrial autophagy system, can selectively clear impaired mitochondria and inhibit mitochondrial dysfunction. Danger signals, such as the release of mtROS and mtDNA released from damaged mitochondria, can activate the NLRP3 inflammasome and further initiate cell and tissue injury $(13,17)$.

Hydrogen $\left(\mathrm{H}_{2}\right)$ serves a protective role in inflammation-related diseases. In our previous investigations, $\mathrm{H}_{2}$ alleviated the excessive release of pro-inflammatory cytokines and oxidative stress factors and protected against cell, tissue and organ damage (18-20). In addition, $\mathrm{H}_{2}$ was shown to regulate the process of autophagy to mitigate the inflammatory response and lung injury in sepsis (19). Therefore, it was hypothesized that NLRP3 activation and autophagy, particularly mitophagy, may regulate the inflammatory response and mitochondrial dysfunction in the pathogenesis of sepsis, which is reversed by $\mathrm{H}_{2}$.

\section{Materials and methods}

Cell culture and treatment. Primary alveolar macrophages (PAMs) were obtained from 60 male C57BL/6 adult mice (weight 20-25 g; age, 6-8 weeks; Laboratory Animal Center of the Academy of Military Medical Sciences). All the mice had free access to standard animal chow and water, and were housed at room temperature $\left(20-22^{\circ} \mathrm{C}\right)$ with $30-70 \%$ humidity on a 12-h light/dark cycle. Following sacrifice of the mice, the lungs were removed and washed in warm sterile phosphate-buffered saline (PBS) supplemented with $5 \mathrm{mM}$ EDTA five times; the bronchoalveolar lavage (BAL) fluid was collected and centrifuged at $500 \mathrm{x} \mathrm{g} 4^{\circ} \mathrm{C}$ for $5 \mathrm{~min}$. The cells were resuspended in DMEM supplemented with $10 \%(\mathrm{v} / \mathrm{v})$ FBS, $1 \%(\mathrm{v} / \mathrm{v})$ penicillin and streptomycin to adjust the cell density to $1.5 \times 10^{6} / \mathrm{ml}$. The cells were seeded into 6 -well plates and incubated at $37^{\circ} \mathrm{C} / 5 \% \mathrm{CO}_{2}$ to allow the cells to adhere for $2 \mathrm{~h}$. The adherent PAMs were then collected for the following experiments. The cells were randomly divided into two for two experiment parts: The first part of the experiment included five groups, as follows: Control, LPS (cells were incubated with $1 \mu \mathrm{g} / \mathrm{ml}$ LPS for $6 \mathrm{~h}$ with normal medium), LPS+ATP (cells were incubated with $1 \mu \mathrm{g} / \mathrm{ml}$ LPS for $5 \mathrm{~h}$ followed by treatment with $5 \mathrm{mM}$ ATP for $1 \mathrm{~h}$ with normal medium), $\mathrm{LPS}+\mathrm{H}_{2}$ (cells were incubated with $1 \mu \mathrm{g} / \mathrm{ml}$ LPS for $6 \mathrm{~h}$ with $\mathrm{H}_{2}$-rich medium), and LPS $+\mathrm{ATP}+\mathrm{H}_{2}$ (cells were incubated with $1 \mu \mathrm{g} / \mathrm{ml} \mathrm{LPS}$ for $5 \mathrm{~h}$ followed by treatment with $5 \mathrm{mM}$ ATP for $1 \mathrm{~h}$ with $\mathrm{H}_{2}$-rich medium). The second part of the experiment included six groups, as follows: LPS, LPS $+\mathrm{H}_{2}$, cecal ligation and puncture (CLP) $+\mathrm{H}_{2+}$ rapamycin (Rap; BioVision, Inc., $10 \mathrm{nM}$ Rap was added to the $\mathrm{H}_{2}$-rich medium $1 \mathrm{~h}$ before LPS treatment), $\mathrm{CLP}+\mathrm{H}_{2}+3-\mathrm{MA}$ (BioVision, Inc.; $1.5 \mathrm{mM} 3-\mathrm{MA}$ was added to the $\mathrm{H}_{2}$-rich medium 1 h before LPS treatment), $\mathrm{CLP}+\mathrm{H}_{2}+\mathrm{NLRP} 3$ inhibitor (20 $\mu \mathrm{M}$ NLRP3 inhibitor MCC950, Sigma Aldrich; Merck $\mathrm{KGaA}$, was added into the $\mathrm{H}_{2}$-rich medium $1 \mathrm{~h}$ before LPS treatment), and CLP+H ${ }_{2+}$ NLRP3 inhibitor+3-MA [20 $\mu \mathrm{M}$ NLRP3 inhibitor and $10 \mathrm{mg} / \mathrm{kg}$ 3-MA, (BioVision, Inc.)] were added to the $\mathrm{H}_{2}$-rich medium $1 \mathrm{~h}$ before LPS treatment). The culture supernatants of the first and the second parts of the experiment were collected to detect IL-1 $\beta$, IL-18, TNF- $\alpha$ and IL- 6 by ELISA. The cells were collected to evaluate mitochondrial function through mitochondrial membrane potential (MMP), the respiratory control ratio (RCR), ATP content and mtDNA, to analyze the protein expression of caspase-1 P10, NLRP3, ASC, microtubule-associated protein 1 light chain 3 (LC3), Beclin 1, PINK1, Parkin and voltage-dependent anion channel (VDAC) by western blotting, and to examine the mRNA expression of LC3, Beclin 1, PINK1 and Parkin by reverse transcription-quantitative polymerase chain reaction (RT-qPCR) analysis.

Animals, CLP procedure and treatment. Another 130 male C57BL/6 mice (weighing 20-25 g and aged 6-8 weeks) were obtained from the Laboratory Animal Center of the Academy 
of Military Medical Sciences (Beijing, China). All mice had free access to standard animal chow and water and were housed at room temperature $\left(20-22^{\circ} \mathrm{C}\right)$ with $30-70 \%$ humidity on a 12/12-h light/dark cycle. All experimental procedures were approved by the Institutional Animal Care and Use Committee of Tianjin Medical University (Tianjin, China) and were performed in accordance with the National Institutes of Health Guide for the Care and Use of Laboratory Animals. All efforts were made to minimize the suffering of the 130 mice ( $\mathrm{n}=23$ /group) used. A sepsis model was established by CLP as previously described (18). The mice were randomly divided into seven groups as follows: Control, $\mathrm{CLP}, \mathrm{CLP}+\mathrm{H}_{2}\left[\mathrm{H}_{2}\right.$-rich saline $(5 \mathrm{ml} / \mathrm{kg})$ was injected i.p. 1 and $6 \mathrm{~h}$ following the sham and CLP procedures], CLP+ $\mathrm{H}_{2}+\mathrm{Rap}$ (Rap, an inducer of autophagy, was administered by intraperitoneal injection at $10 \mathrm{mg} / \mathrm{kg}$ BW $1 \mathrm{~h}$ before CLP; $\mathrm{H}_{2}$ treatment was as in the $\mathrm{CLP}+\mathrm{H}_{2}$ group), $\mathrm{CLP}+\mathrm{H}_{2+} 3-\mathrm{MA}$ (3-MA, an inhibitor of autophagy, was administered by intraperitoneal injection at $15 \mathrm{mg} / \mathrm{kg} \mathrm{BW} 1 \mathrm{~h}$ before CLP; $\mathrm{H}_{2}$ treatment was as for the $\mathrm{CLP}+\mathrm{H}_{2}$ group). Subsequently, the mice were anesthetized with sodium pentobarbital $(50 \mathrm{mg} / \mathrm{kg}$, intraperitoneally) and sacrificed via decollation; lung tissues were collected to determine the tissue pathological scores by hematoxylin and eosin (H\&E) staining, wet-to-dry (W/D) weight ratio and myeloperoxidase (MPO) activity. BAL fluid was collected to analyze the total proteins in the lung. Liver and kidney tissues were collected to investigate pathological scores. Blood and tissue homogenates of the lung, liver and kidney were obtained to detect the biochemical parameters of the liver and kidney, and the levels of IL-1 $\beta$, IL-18 and TNF- $\alpha$ by ELISA. Other parts of the lung, liver and kidney were collected and proteins were extracted for the detection of procaspase-1, caspase-1 P10, NLRP 3 and ASC by western blotting. The survival rate was analyzed 1,2,3, 5 and 7 days after surgery.

ELISA. The supernatants and tissues of the lung, liver and kidney were collected. The tissue samples were homogenized and centrifuged at $10,000 \mathrm{~g}$ for $10 \mathrm{~min}$ at $4^{\circ} \mathrm{C}$, and the supernatants were used to analyze IL-1 $\beta$ (cat. no. RLB00; R\&D Systems, Inc.), IL-18 (cat. no. 7625; R\&D Systems, Inc.), TNF- $\alpha$ (cat. no. RTA00; R\&D Systems, Inc.) and IL-6 (cat. no. R6000B; R\&D Systems, Inc.) using ELISA commercial kits according to the manufacturer's instructions.

Transmission electron microscopy (TEM). The lung tissues were harvested, cut into small pieces and immediately fixed in $0.25 \%$ glutaraldehyde at $4^{\circ} \mathrm{C}$ overnight. The macrophages were isolated, concentrated and fixed in $0.25 \%$ glutaraldehyde at $4^{\circ} \mathrm{C}$ overnight. Following fixation and dehydration, $50-\mathrm{nm}$ sections were prepared with using an ultramicrotome (Ultracut UCT; Leica Microsystems, Inc.). The sections were stained with $2 \%$ uranyl acetate for $30 \mathrm{~min}$ at $4^{\circ} \mathrm{C}$, followed by staining in lead citrate solution $30 \mathrm{~min}$ at room temperature. The sections were observed using a transmission electron microscope (Hitachi, Ltd., Tokyo, Japan).

Western blot assay. Macrophages and the lung, liver and kidney tissues were harvested and lysed in RIPA lysis buffer. Protein quantitation was performed with the BCA assay kit (Thermo Fisher Scientific, Inc.). Protein $(15 \mu \mathrm{g})$ was loaded onto 10\% SDA-PAGE gels and electrophoretically transferred onto PVDF membranes (EMD Millipore) by conventional wet blotting. The membranes were blocked with blocking buffer (5\% non-fat dry milk) for $1 \mathrm{~h}$, and then incubated with primary antibodies against procaspase-1, caspase-1 P10 (cat. no. sc-56036, 1:200, Santa Cruz Biotechnology, Inc.), NLRP3 (cat. no. ab214185; 1:500, Abcam), ASC (cat. no. sc-514414, 1:200, Santa Cruz Biotechnology, Inc.), LC3 (cat. no. ab48394; 1:500, Abcam), Beclin 1 (cat. no. ab62557; 1:500, Abcam), PINK1 (cat. no. ab23707; 1:500, Abcam), Parkin (cat. no. ab77924; 1:500, Abcam), VDAC (cat. no. ab14734; 1:200, Abcam) and $\beta$-actin (cat. no. ab8227; 1:2,000, Abcam) in blocking buffer at $4^{\circ} \mathrm{C}$ overnight. Subsequently, the membranes were washed with TBST three times, followed by incubation with corresponding horseradish peroxidase-conjugated goat IgG secondary antibodies (cat. nos. ab6721 and ab6728; 1:5,000, Abcam) at $37^{\circ} \mathrm{C}$ for $1.5 \mathrm{~h}$. Following washing with TBST three times, the blots were analyzed with ECL reagent (EMD Millipore). The membranes were visualized using the UVP Bio-Imaging System. The blot densities were analyzed with Quantity One (v4.6) software (Bio-Rad Laboratories, Inc.). Protein expression was normalized to $\beta$-actin.

$R T-q P C R$ analysis. RNA was isolated from cells using the TRIzol reagent (cat. no. 15596026; Thermo Fisher Scientific, Inc.) according to the manufacturer's protocol. cDNA was obtained using a RevertAid First Strand cDNA Synthesis kit (cat. no. K1621; Thermo Fisher Scientific, Inc.). relative mRNA expression was detected by qPCR using SYBR PCR Master Mix (Thermo Fisher Scientific, Inc.) on a 7500 Real-time PCR system (Thermo Fisher Scientific, Inc.). The amplification conditions were as follows: Pre-degeneration at $95^{\circ} \mathrm{C}$ for $10 \mathrm{~min}$, then 40 cycles of denaturing at $95^{\circ} \mathrm{C}$ for $15 \mathrm{sec}$, annealing at $60^{\circ} \mathrm{C}$ for $30 \mathrm{sec}$ and extension at $72^{\circ} \mathrm{C}$ for $30 \mathrm{sec}$, and a final extension at $72^{\circ} \mathrm{C}$ for $5 \mathrm{~min}$. The gene-specific primer sequences are listed in Table I. Relative fold expressions were normalized to GAPDH and calculated using the $2^{-\Delta \Delta C q}$ method (21).

\section{Mitochondrial function}

MMP measurement. MMP was identified using JC-1 dye (Beyotime Institute of Biotechnology) according to the manufacturer's instructions. Following the experiment, the cells were dyed with $\mathrm{JC}-1$ staining solution at $37^{\circ} \mathrm{C}$ for $30 \mathrm{~min}$, and the fluorescent properties changed from green to red when the level of MMP was high. Red fluorescent JC-1 aggregates form in hyperpolarized membranes, whereas green fluorescent monomeric forms indicate membrane depolarization. The higher the ratio of red to green fluorescence, the more intact the mitochondrial membrane.

$R C R$ analysis. The isolation of intact mitochondria from cells was performed according to the method described by Iglesias-González et al (22). The cells were centrifuged at $1,000 \mathrm{x} \mathrm{g}$ for $10 \mathrm{~min}$ at $4^{\circ} \mathrm{C}$, following which the supernatant was collected and centrifuged again at 10,000 $\mathrm{x}$ g for $10 \mathrm{~min}$ at $4^{\circ} \mathrm{C}$. The resulting mitochondrial pellet was gently washed twice, resuspended and diluted in a minimal volume of isolation buffer. All steps of mitochondrial isolation were performed on ice at $4^{\circ} \mathrm{C}$. The protein concentration was determined 
Table I. Primer sequences.

\begin{tabular}{lll}
\hline Gene & Primer & \multicolumn{1}{c}{ Sequence ('5-3') } \\
\hline LC3 & Forward & TCCACTCCCATCTCCGAAGT \\
& Reverse & TTGCTGTCCCGAATGTCTCC \\
Beclin 1 & Forward & ACCAGCGGGAGTATAGTGAGT \\
& Reverse & CAGCTGGATCTGGGCGTAG \\
PINK1 & Forward & CCATCGGGATCTCAAGTCCG \\
& Reverse & GATCACTAGCCAGGGACAGC \\
Parkin & Forward & TTCCCGTTCAGCTCTGGG \\
& Reverse & CCCTGCATCCACTGGTGC \\
GAPDH & Forward & GTGTTTCCTCGTCCCGTAGA \\
& Reverse & AATCTCCACTTTGCCACTGC \\
\hline
\end{tabular}

LC3, microtubule-associated protein 1 light chain 3; PINK1, PTEN-induced putative kinase 1.

using the Pierce BCA Protein Assay kit (Thermo Fisher Scientific, Inc.). The isolated mitochondria $(1 \mathrm{mg} / \mathrm{ml})$ were incubated with $2 \mathrm{ml}$ respiration buffer $(70 \mathrm{mmol} / \mathrm{l}$ sucrose, $1 \mathrm{mmol} / \mathrm{l}$ EDTA, $225 \mathrm{mmol} / \mathrm{l}$ mannitol, $200 \mathrm{mmol} / 1 \mathrm{KH}_{2} \mathrm{PO}_{4}$, $200 \mathrm{mmol} / 1 \mathrm{~K}_{2} \mathrm{HPO}_{4}$ and $0.1 \% \mathrm{BSA}$; pH 7.4) at $30^{\circ} \mathrm{C}$ in a temperature-controlled water bath with continuous stirring. The mitochondrial oxygen consumption was evaluated with a Clark-type electrode (Hansatech-Instruments, Ltd.). The state 3 respiration rate reflects the oxygen consumption rate in the presence of $\mathrm{ADP}$, whereas the state 4 respiration rate reflects the oxygen consumption rate when ADP is exhausted. The RCRs were estimated as state $3 /$ state 4 .

ATP detection. The ATP content was determined with the ATP Bioluminescence Assay kit (no. 11699709001, Roche Diagnostics) according to the manufacturer's instructions.

$m t D N A$ detection. Total DNA was isolated from cells with a DNeasy Blood \& Tissue kit according to the manufacturer's instructions (Qiagen, Inc.). The quality of the extracted DNA was evaluated by qPCR analysis. The cycling program for amplification was $95^{\circ} \mathrm{C}$ for $2 \mathrm{~min}$, followed by $95^{\circ} \mathrm{C}$ for $10 \mathrm{sec}$, $60^{\circ} \mathrm{C}$ for $30 \mathrm{sec}$, and $95^{\circ} \mathrm{C}$ for $10 \mathrm{sec}$ for 40 cycles. The copy number of mtDNA was normalized to that of nuclear DNA (cytochrome $c$ oxidase I/18S ribosomal RNA). The mitochondrial primer sequences were selected and were as follows: Mouse cytochrome $c$ : Forward 5'-TTTGGGTCCCTTCTA GGAGTC-3' and reverse 5'-CCGACATGAAGGAATAAG CAA-3'; murine $\beta 2$-microglobulin: Forward 5'-ATGGGA AGCCGAACATACTG-3' and reverse 5'-CAGTCTCAGTGG GGGTGAAT-3'. The relative gene expression was analyzed, and the ratio of $\mathrm{mtDNA} / \mathrm{nDNA}$ was $100 \%$ in the control or LPS groups, according to CFX Manager 2.1 software (Bio-Rad Laboratories, Inc.).

Determination of mtROS. mtROS production was measured using the ROS-specific fluorescent probe, dichloro-dihydro-fluorescein diacetate (DCFH-DA). The fluorescence intensity was measured in a fluorescent microplate reader (BioTek Instruments, Inc.). The fluorescence intensity was normalized to that of the control group.

Tissue pathological scores. Following the experiment, the lung, liver and kidney tissues were perfused with $10 \%$ formalin and fixed for $24 \mathrm{~h}$ at room temperature. After embedding in paraffin, $5 \mu \mathrm{m}$ sections of lung tissues were cut, dewaxed and stained with H\&E. Histopathological analysis of the tissues was performed following staining with H\&E. The sections were observed and photographed under a microscope (Biorevo BZ-9000; Keyence Corporation), and evaluated by at least two pathologists who were blinded to the study protocol. The scoring standard is shown in Table SI.

Lung MPO. The lung tissues were harvested and collected to measure the lung MPO activity using a commercial kit (cat. no. K747; BioVision, Inc.) following the manufacturer's instructions.

$B A L$ total protein. The mice were sacrificed, and a small catheter was placed in the trachea and secured. Isotonic saline (500 $\mu \mathrm{l})$ was slowly instilled and then gently withdrawn. This fluid was instilled and withdrawn three times in total. The BALF was centrifuged at $1,500 \mathrm{~g}$ for $10 \mathrm{~min}$, at $4^{\circ} \mathrm{C}$ and the supernatant was used to assess the total protein in the BAL using a protein assay commercial kit (Bio-Rad Laboratories, Inc.).

Lung W/D ratio. The harvested wet lung was weighed and then placed in an oven for $24 \mathrm{~h}$ at $80^{\circ} \mathrm{C}$. The lung was then weighed when it had dried.

Biochemical parameters of the liver and kidney. Blood was collected for the measurement of biochemical parameters [alanine aminotransferase (ALT), aspartate aminotransferase (AST), blood urea nitrogen (BUN) and creatinine $(\mathrm{Cr})]$ with commercial ELISA kits (R\&D Systems, Inc.) according to the manufacturer's instructions.

Statistical analysis. The survival rates are expressed as percentages and analysis was performed with the log-rank test. All other results of experiments are expressed as the mean \pm standard deviation and were analyzed by one-way ANOVA with the Tukey's multiple comparisons test. Statistical analyses were performed using GraphPad Prism (v.5.0; GraphPad Software, Inc.). In all tests, $\mathrm{P}<0.05$ was considered to indicate a statistically significant difference.

\section{Results}

$\mathrm{H}_{2}$ downregulates NLRP3-mediated cytokine release following LPS and ATP stimulation in PAMs. The ATP-driven activation of caspase-1 is a common model for NLRP3 inflammasome-mediated caspase-1 activation in LPS-induced macrophages $(11,12)$. To investigate the effect of $\mathrm{H}_{2}$ on cytokines and inflammasome pathways, LPS, ATP and $\mathrm{H}_{2}$-rich medium were used to treat macrophages. As shown in Fig. 1, the expression levels of IL-1 $\beta$ (Fig. 1A), IL-18 (Fig. 1B), TNF- $\alpha$ (Fig. 1C), IL-6 (Fig. 1D) and caspase-1 P 10 (Fig. 1E) were increased in the LPS and LPS+ATP groups compared 

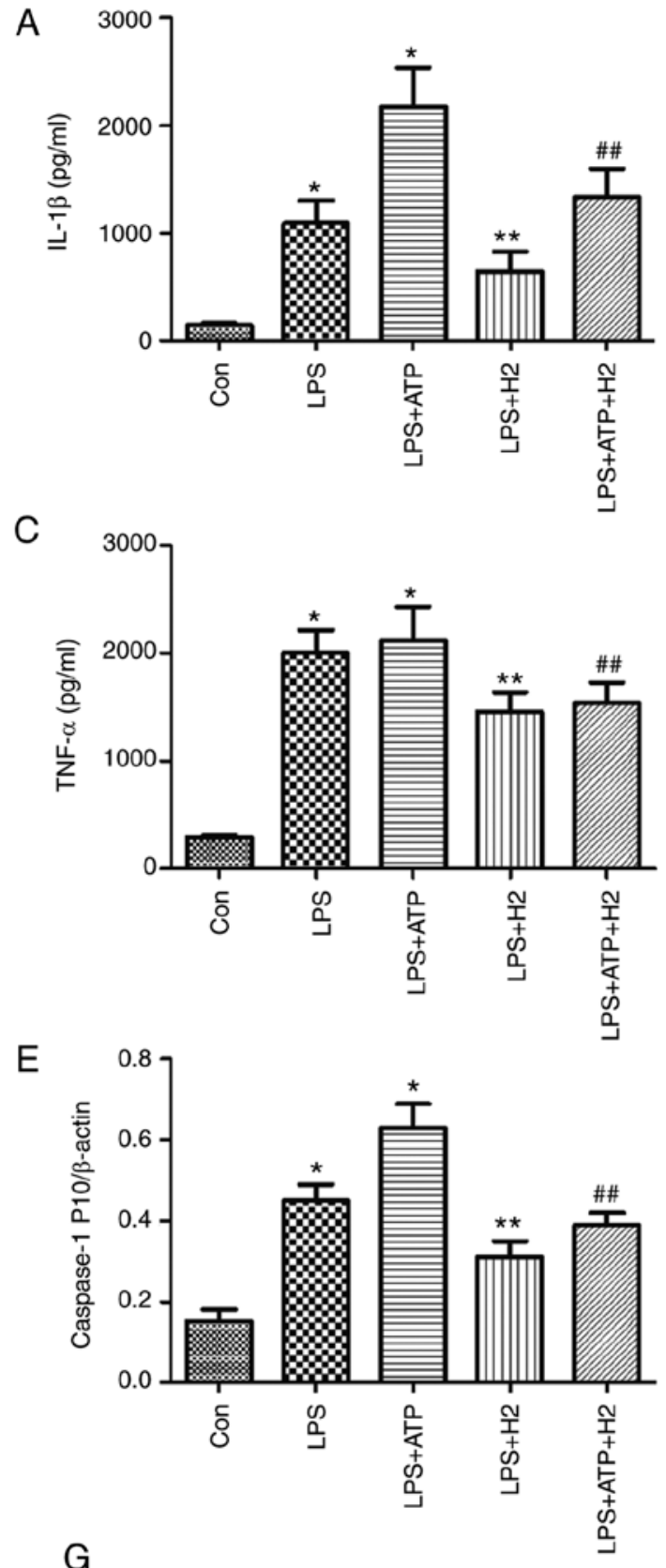

G

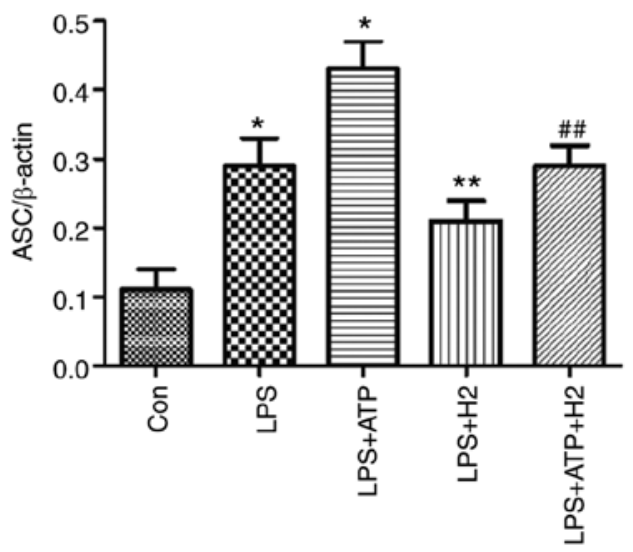

B
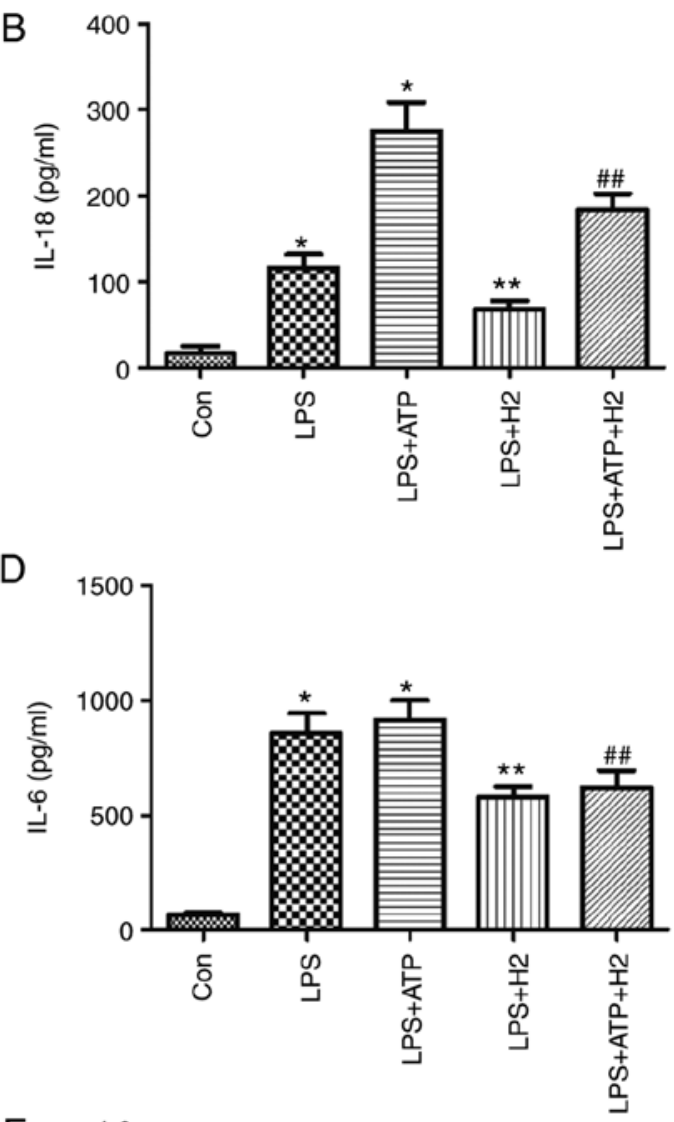

$\mathrm{F}$

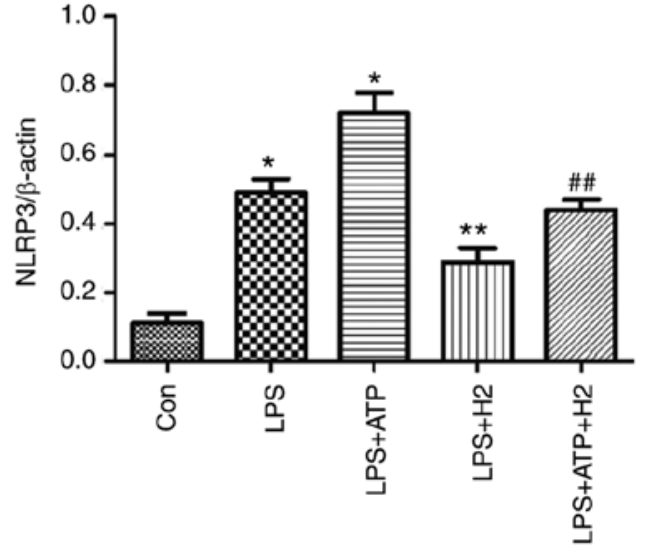

$\mathrm{H}$

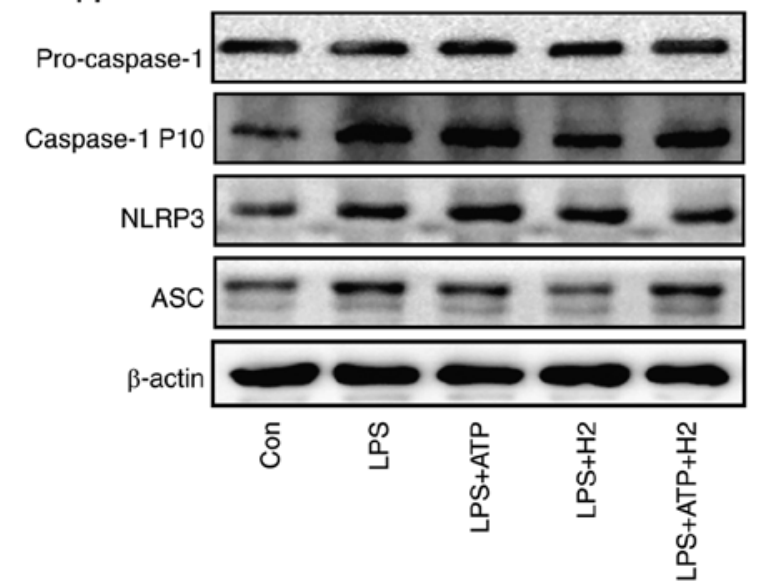

Figure 1. Cytokine and inflammasome protein expression in macrophages treated with LPS, ATP and $\mathrm{H}_{2}$. Macrophages were exposed to by LPS, ATP and $\mathrm{H}_{2}$. The culture supernatants were collected to detect cytokines (A) IL-1 $\beta$, (B) IL-18, (C) TNF- $\alpha$ and (D) IL- 6 by ELISA, and cells were harvested to measure the expression of (E) caspase-1, (F) NLRP3 and (G) ASC by western blotting. (H) Blots of caspase-1, NLRP3 and ASC in cells. Data are expressed as the mean \pm standard deviation $(n=6)$. ${ }^{*} \mathrm{P}<0.05$ vs. Con group, ${ }^{* *} \mathrm{P}<0.05$ vs. LPS group, ${ }^{\# \#} \mathrm{P}<0.05$ vs. LPS $+\mathrm{ATP}$ group. LPS, lipopolysaccharide; IL, interleukin; TNF, tumor necrosis factor; ASC, apoptosis-associated speck-like protein containing a CARD; NLRP3, NACHT, LRR and PYD domains-containing protein 3; H $_{2}$, hydrogen; Con, control. 

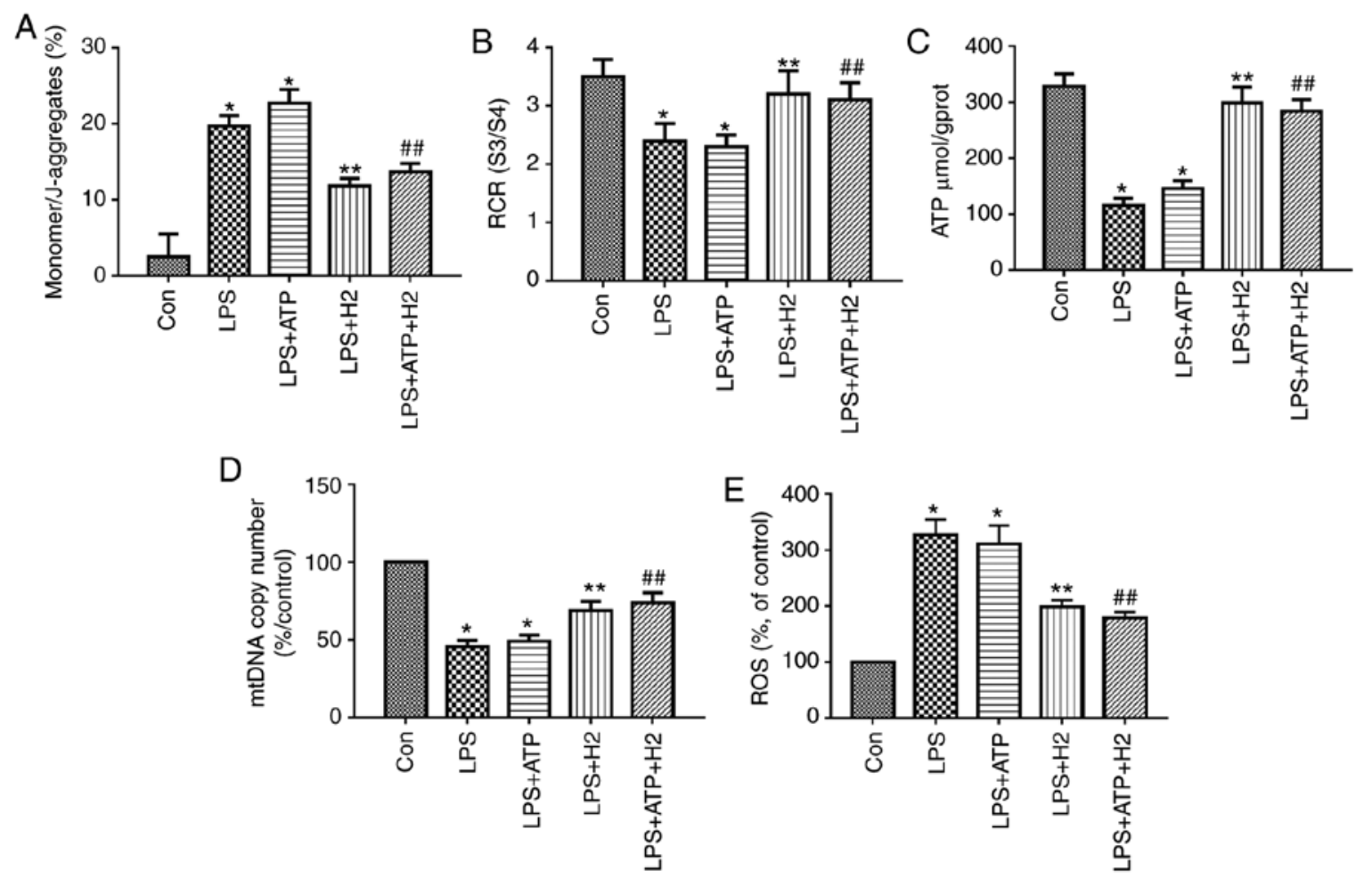

Figure 2. Mitochondria and mtDNA in macrophages treated with LPS, ATP and $\mathrm{H}_{2}$. Macrophages were treated by LPS, ATP and $\mathrm{H}_{2}$. Cells were harvested to measure (A) MMP, (B) RCR, (C) ATP, (D) mtDNA and (E) ROS release. Data are expressed as the mean \pm standard deviation ( $\mathrm{n}=6$ ). " $\mathrm{P}<0.05$ vs. Con group, ${ }^{* *} \mathrm{P}<0.05$ vs. LPS group, ${ }^{\# \#} \mathrm{P}<0.05$ vs. LPS+ATP group. mtDNA, mitochondrial DNA; LPS, lipopolysaccharide; MMP, mitochondrial membrane potential; $\mathrm{RCR}$, respiratory control ratio; ROS, reactive oxygen species; $\mathrm{H}_{2}$, hydrogen; Con, control.

with those in the Con group $(\mathrm{P}<0.05)$; however, no significant differences in TNF- $\alpha$ (Fig. 1C) or IL-6 (Fig. 1D) were detected between the LPS and LPS+ATP groups $(\mathrm{P}>0.05) . \mathrm{H}_{2}$ treatment alleviated the increased expression of IL-1 $\beta$ (Fig. 1A), IL-18 (Fig. 1B) and caspase-1 P 10 (Fig. 1E and H) compared with expression in the LPS and LPS+ATP groups $(\mathrm{P}<0.05)$.

Macrophages can express intracellular Nod-like receptors (NLRs) when induced by detrimental stimulation. The NLRP3 inflammasome is a critical member of the NLR family, as it interacts with ASC and sequentially regulates the expression of mature IL- $1 \beta$, IL-18 and caspase- 1 . The NLRP3 inflammasome pathway protein was investigated in the present study. Consistent with the changes in IL-1 $\beta$, IL-18 and caspase-1 P10, LPS and ATP activated the inflammasome, NLRP3 (Fig. 1F and $\mathrm{H}$ ) and increased the expression of ASC (Fig. $1 \mathrm{G}$ and $\mathrm{H})(\mathrm{P}<0.05)$, and there was a significant difference between groups LPS and LPS+ATP $(\mathrm{P}<0.05)$. The expression levels of NLRP3 (Fig. 1F and $\mathrm{H}$ ) and ASC (Fig. 1G and $\mathrm{H}$ ) were reduced in the LPS $+\mathrm{H}_{2}$ and $\mathrm{LPS}+\mathrm{ATP}+\mathrm{H}_{2}$ groups compared with those in the LPS and LPS+ATP groups, respectively $(\mathrm{P}<0.05)$. These data indicated that LPS and ATP activated the inflammasome and promoted the maturation and release of cytokines, whereas $\mathrm{H}_{2}$ alleviated inflammasome activation and the release of cytokines in response to LPS and ATP.

$\mathrm{H}_{2}$ improves the mitochondrial dysfunction induced by LPS and ATP in PAMs. Mitochondrial function was assessed through MMP, RCR, ATP content and ROS. mtDNA is a damage-associated molecular pattern. When mitochondria are injured, mtDNA is released into the cytosol. LPS and ATP treatment reduced MMP (the monomer/J-aggregates value was upregulated), mtDNA copy number, RCR and ATP content, and increased ROS release in macrophages (Fig. 2A-E, $\mathrm{P}<0.05$ ); however, there was no significant difference between the LPS and LPS+ATP groups (Fig. $2 \mathrm{~A}, \mathrm{P}>0.05$ ). $\mathrm{H}_{2}$-rich medium markedly increased MMP (the monomer/J-aggregates value was downregulated), mtDNA copy number, RCR and ATP content, and reduced ROS release in the LPS and ATP-treated cells compared with results in the LPS group and LPS+ATP group, respectively (Fig. $2 \mathrm{~A}-\mathrm{E}, \mathrm{P}<0.05$ ). These data suggest that $\mathrm{H}_{2}$-rich medium treatment alleviated the mitochondrial dysfunction and injury in macrophages induced by LPS and ATP.

Effect of $\mathrm{H}_{2}$ on autophagy-related proteins in alveolar macrophages during LPS and ATP treatment. Autophagy is a vital process responsible for removing senescent or damaged organelles. LC3I, a cytosolic form of LC3, is conjugated to phosphatidylethanolamine to form LC3-phosphatidylethanolamine conjugate (LC3II), which reflects the autophagic activity. Beclin 1 is a core component of the autophagy machinery. LPS or LPS+ATP induced the increasing of number of autophagosomes compared with that in the Con group (Fig. 3A, $\mathrm{P}<0.05$ ), $\mathrm{H}_{2}$ treatment further promoted the number of autophagosomes in the $\mathrm{LPS}+\mathrm{H}_{2}$ group and LPS $+\mathrm{ATP}+\mathrm{H}_{2}$ group compared with that in the LPS group or LPS+ATP group, respectively (Fig. 3A, P<0.05). As shown in Fig. 3B, C and G, LPS and ATP enhanced autophagic activity, as indicated by the alternation of LC3I into LC3II and the increased expression 

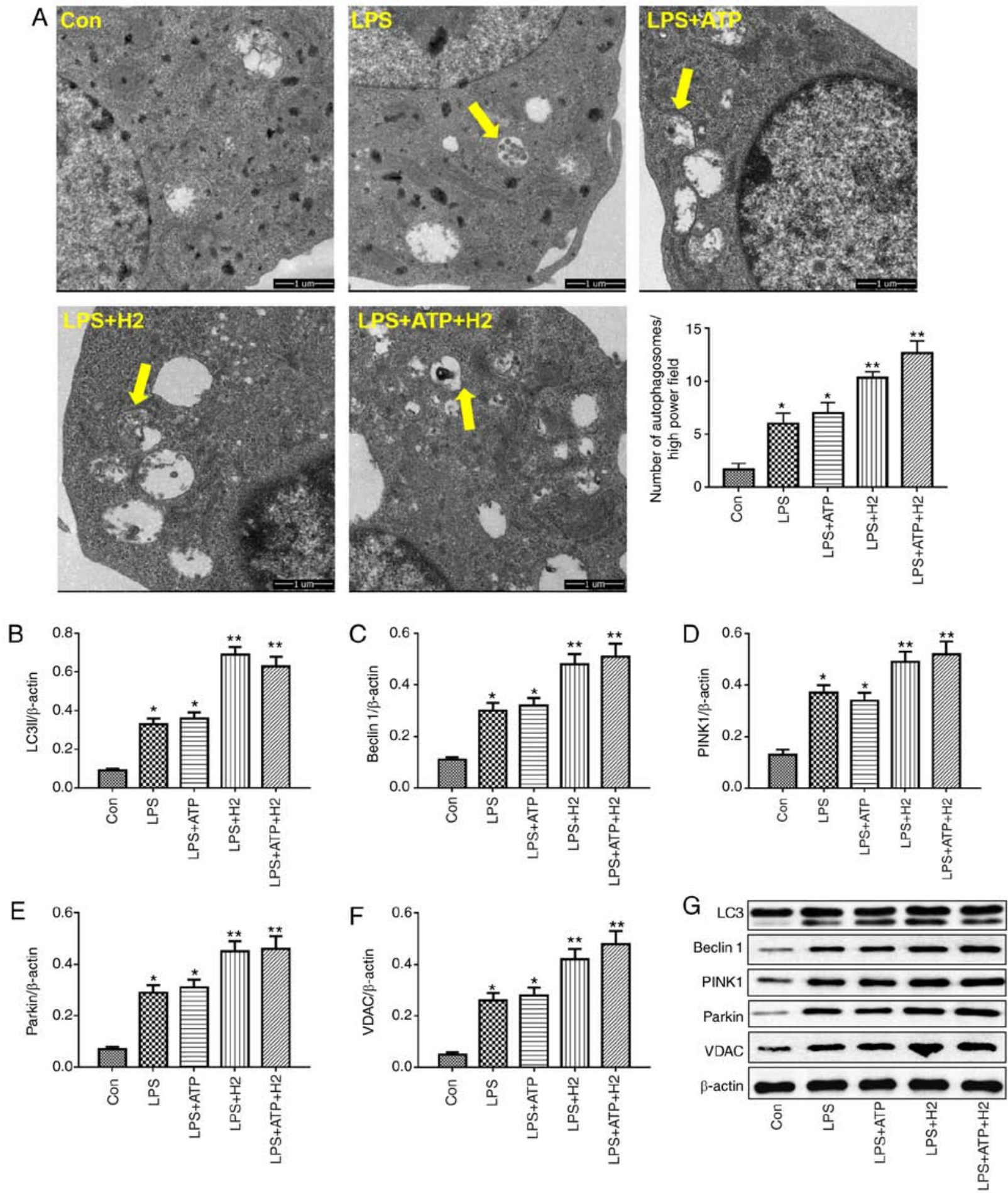

Figure 3. Autophagy-related protein expression in macrophages treated with LPS, ATP and $\mathrm{H}_{2}$. Macrophages were treated by LPS, ATP and $\mathrm{H}_{2}$. Cells were harvested to measure the (A) number of autophagosomes (indicated by yellow arrows; magnification, x10,000), and the expression of (B) LC3, (C) Beclin 1, (D) PINK1, (E) Parkin and (F) VDAC by western blotting. (G) Representative blots of LC3, Beclin 1, Parkin and VDAC in cells. Data are expressed as the mean \pm standard deviation $(\mathrm{n}=6) .{ }^{*} \mathrm{P}<0.05$ vs. Con group, ${ }^{* *} \mathrm{P}<0.05$ vs. LPS group. LPS, lipopolysaccharide; LC3, microtubule-associated protein 1 light chain 3; PINK1, PTEN-induced putative kinase 1; VDAC, voltage-dependent anion channel; $\mathrm{H}_{2}$, hydrogen; Con, control.

of Beclin 1 in macrophages $(\mathrm{P}<0.05)$, whereas $\mathrm{H}_{2}$ further promoted the process of autophagy. The expression levels of LC3II and Beclin 1 were further elevated in the LPS $+\mathrm{H}_{2}$ and LPS $+\mathrm{ATP}+\mathrm{H}_{2}$ groups compared with those in the LPS or LPS+ATP groups, respectively $(\mathrm{P}<0.05)$.

Parkin is the most well-known E3 ubiquitin ligase involved in mitophagy. The PINK-Parkin pathway serves a critical role in mitophagy (23). VDACs are necessary for efficient recruitment of Parkin to the mitochondria during the process of mitophagy. Consistent with the variations in LC3 and Beclin 1, LPS and ATP also induced mitophagic activity, with increased expression of PINK1, Parkin and VDAC (Fig. 3D-G, P<0.05). Compared with the LPS and LPS+ATP groups, $\mathrm{H}_{2}$ treatment further increased the expression of PINK1, Parkin and 
VDAC in the LPS $+\mathrm{H}_{2}$ and LPS + ATP $+\mathrm{H}_{2}$ groups (Fig. 3D-G, $\mathrm{P}<0.05)$. This autophagy-related protein increase, particularly mitophagic protein, indicated that $\mathrm{H}_{2}$ was able to increase mitophagic activity in macrophages stimulated by LPS and ATP.

$\mathrm{H}_{2}$ regulates NLRP3-mediated cytokine release via autophagy in LPS-treated macrophages. Accumulated evidence has verified that autophagy regulates the NLRP3 inflammasome activation as an upstream pathway (13). To examine the induction and inhibition of autophagy, autophagy-related gene expression was detected following treatment with autophagy inducer (Rap) or inhibitor (3-MA). It was observed that the mRNA expression levels of LC3, Beclin 1, PINK1 and Parkin were increased in the LPS $+\mathrm{H}_{2}+$ Rap group and reduced in the LPS $+\mathrm{H}_{2}+3$-MA group compared with those in the $\mathrm{LPS}+\mathrm{H}_{2}$ group (Fig. S1, $\mathrm{P}<0.05$ ). To further investigate the effect of $\mathrm{H}_{2}$ on NLRP3 inflammasome activation via autophagy, the cells were treated with autophagy inducer Rap and inhibitor 3-MA, and NLRP3 inhibitor MCC950. Compared with the levels in the LPS group, the expression levels of IL-1 $\beta$ (Fig. 4A), IL-18 (Fig. 4B), TNF- $\alpha$ (Fig. 4C), IL-6 (Fig. 4D) and caspase-1 P10 (Fig. 4E) were considerably reduced in the $\mathrm{LPS}+\mathrm{H}_{2}, \mathrm{LPS}+\mathrm{H}_{2}+\mathrm{Rap}$ and $\mathrm{LPS}+\mathrm{H}_{2}+\mathrm{NLRP} 3$ inhibitor groups $(\mathrm{P}<0.05)$. Compared with the LPS $+\mathrm{H}_{2}$ group, the downregulation of IL-1 $\beta$ (Fig. 4A), IL-18 (Fig. 4B), TNF- $\alpha$ (Fig. 4C), IL-6 (Fig. 4D) and caspase-1 P10 (Fig. 4E) was significant in the LPS $+\mathrm{H}_{2}+$ Rap group ( $\left.\mathrm{P}<0.05\right)$. IL-1 $\beta$ (Fig. 4A), IL-18 (Fig. 4B) and caspase-1 P10 (Fig. 4E) were also significantly decreased in the LPS $+\mathrm{H}_{2}+\mathrm{NLRP} 3$ inhibitor group $(\mathrm{P}<0.05)$; however, TNF- $\alpha$ (Fig. 4C) and IL-6 (Fig. 4D) did not differ significantly between the LPS $+\mathrm{H}_{2}$ and LPS $+\mathrm{H}_{2}+\mathrm{NLRP} 3$ inhibitor groups ( $\mathrm{P}>0.05)$; Compared with expression in the $\mathrm{LPS}+\mathrm{H}_{2}$ group, IL-1 $\beta$ (Fig. 4A), IL-18 (Fig. 4B), TNF- $\alpha$ (Fig. 4C), IL-6 (Fig. 4D) and caspase-1 P10 (Fig. 4E) were increased in the LPS $+\mathrm{H}_{2}+3$-MA group $(\mathrm{P}<0.05)$. To investigate whether $\mathrm{H}_{2}$ reduced the activation of NLRP3 via autophagy, 3-MA was used to inhibit autophagy in the LPS $+\mathrm{H}_{2}+\mathrm{NLRP} 3$ inhibitor group; the result demonstrated that, compared with the LPS $+\mathrm{H}_{2}+\mathrm{NLRP} 3$ inhibitor group, all the above-mentioned indicators (Fig. 4A-E) were markedly upregulated in the LPS $+\mathrm{H}_{2}+3-\mathrm{MA}+\mathrm{NLRP} 3$ inhibitor group $(\mathrm{P}<0.05)$.

Consistent with the results in cytokines, NLRP3 and ASC were reduced in the LPS $+\mathrm{H}_{2}$ group compared with levels in the LPS group; the autophagy inducer and NLRP3 inhibitor further reduced the expression of NLRP3 and ASC in macrophages treated with LPS (Fig. 4F and G, P<0.05). Compared with those in the LPS $+\mathrm{H}_{2}$ group, the expression levels of NLRP3 and ASC were increased in the $\mathrm{LPS}+\mathrm{H}_{2}+3-\mathrm{MA}$ group. Compared with expression in the LPS $+\mathrm{H}_{2}+\mathrm{NLRP} 3$ inhibitor group, NLRP3 and ASC were significantly aggravated in the LPS $+\mathrm{H}_{2}+3-\mathrm{MA}+\mathrm{NLRP} 3$ inhibitor group (Fig. $4 \mathrm{~F}$ and $\mathrm{G}$, $\mathrm{P}<0.05$ ). These results suggest that $\mathrm{H}_{2}$ and Rap synergistically induced autophagy and inhibited NLRP3 inflammasome activation and that $\mathrm{H}_{2}$ reversed this inhibition of the NLRP3 inflammasome by the autophagy inhibitor 3-MA.

$\mathrm{H}_{2}$ improves mitochondrial dysfunction via the autophagy-mediated NLRP3 inflammasome pathway in LPS-treated macrophages. To investigate the effect of $\mathrm{H}_{2}$ on mitochondrial dysfunction and damage via the autophagy-mediated NLRP3 inflammasome pathway, the cells were treated with autophagy inducer Rap and inhibitor 3-MA, and with the NLRP3 inhibitor MCC950. MMP, RCR, ATP content, mtDNA and ROS were assessed to verify this hypothesis. $\mathrm{H}_{2}$ treatment increased MMP (the monomer/J-aggregates value was downregulated), RCR, ATP content and mtDNA copy number and reduced ROS release in the LPS $+\mathrm{H}_{2}$ group compared with results in the LPS group (Fig. 5A-E, P<0.05). The autophagy inducer Rap and NLRP3 inhibitor further increased MMP (the monomer/J-aggregates value was downregulated), RCR, ATP content and mtDNA copy number and reduced $\mathrm{ROS}$ release in the $\mathrm{LPS}+\mathrm{H}_{2}+\mathrm{Rap}$ and $\mathrm{LPS}+\mathrm{H}_{2}+\mathrm{NLRP} 3$ inhibitor groups compared with results in the LPS $+\mathrm{H}_{2}$ group (Fig. 5A-D, P<0.05). The autophagy inhibitor 3-MA markedly reduced MMP (the monomer/J-aggregates value was increased), RCR, ATP content and mtDNA copy number and increased ROS release in the LPS $+\mathrm{H}_{2}+3-\mathrm{MA}$ group compared with results in the $\mathrm{LPS}+\mathrm{H}_{2}$ group (Fig. 5A-E, $\mathrm{P}<0.05$ ). Compared with the LPS $+\mathrm{H}_{2}+\mathrm{NLRP} 3$ inhibitor group, MMP (the monomer/J-aggregates value was increased), RCR, ATP content and mtDNA copy number were significantly reduced and ROS release was increased in the LPS $+\mathrm{H}_{2}+3-\mathrm{MA}+\mathrm{NLRP} 3$ inhibitor group (Fig. 5A-E, P<0.05).

\section{$\mathrm{H}_{2}$ improves survival rate via the autophagy-mediated NLRP3 inflammasome pathway in mice following CLP. To investigate the effect of the autophagy-mediated NLRP3 inflammasome pathway on $\mathrm{H}_{2}$ promoting the survival rate in CLP mice, the mice were treated with autophagy inducer Rap and inhibitor 3-MA following CLP, and the survival rate at 1, 2, 3, 5 and 7 days was recorded. The results (Fig. 6K) revealed that the survival rate was higher in the $\mathrm{CLP}+\mathrm{H}_{2}$ and $\mathrm{CLP}+\mathrm{H}_{2}+\mathrm{Rap}$ groups compared with that in the CLP group $(\mathrm{P}<0.05)$. Compared with that in the $\mathrm{CLP}+\mathrm{H}_{2}$, group, the survival rate was lower in the $\mathrm{CLP}+\mathrm{H}_{2}+3-\mathrm{MA}$ group $(\mathrm{P}<0.05)$.}

$\mathrm{H}_{2}$ improves lung, kidney and liver dysfunction via the autophagy-mediated NLRP3 inflammasome pathway in mice following CLP. Consistent with our previous research, CLP induced severe acute lung injury (ALI) at $24 \mathrm{~h}$ post-CLP, as shown by lung histopathology, lung MPO activity, protein concentration in BAL fluid and lung W/D ratio (Fig. 6A-D and Fig. $\mathrm{S} 2, \mathrm{P}<0.05) . \mathrm{H}_{2}$ ameliorated ALI via decreasing the levels of these indicators (Fig. 6A-D, P<0.05). To evaluate the effect of the autophagy-mediated NLRP3 inflammasome pathway on $\mathrm{H}_{2}$ improving organ dysfunction in vivo, ALI was assessed through inducing or inhibiting autophagy or NLRP3 inflammasome activation. The autophagy inducer and NLRP3 inhibitor ameliorated lung histopathology, lung MPO activity, protein concentration in BAL fluid and lung W/D ratio following $\mathrm{CLP}+\mathrm{H}_{2}$ treatment compared results in the $\mathrm{CLP}+\mathrm{H}_{2}$ group. However, 3-MA treatment reversed the beneficial effect of $\mathrm{H}_{2}$ and the NLRP3 inhibitor on lung histopathology, lung MPO activity, protein concentration in BAL fluid and lung W/D ratio in mice following CLP and $\mathrm{H}_{2}$ treatment (Fig. 6A-D, $\mathrm{P}<0.05$ )

Liver and kidney injury exhibited the same trend as ALI in the present study. $\mathrm{H}_{2}$ significantly improved the histopathological changes of the liver and kidney, and the serum levels of ALT, AST, Cr and BUN in the CLP mice (Fig. 6E-J, Fig. S2, 
A

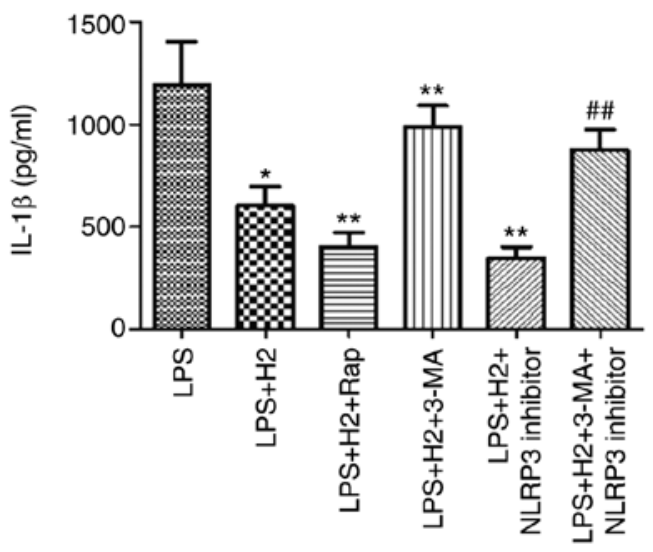

C

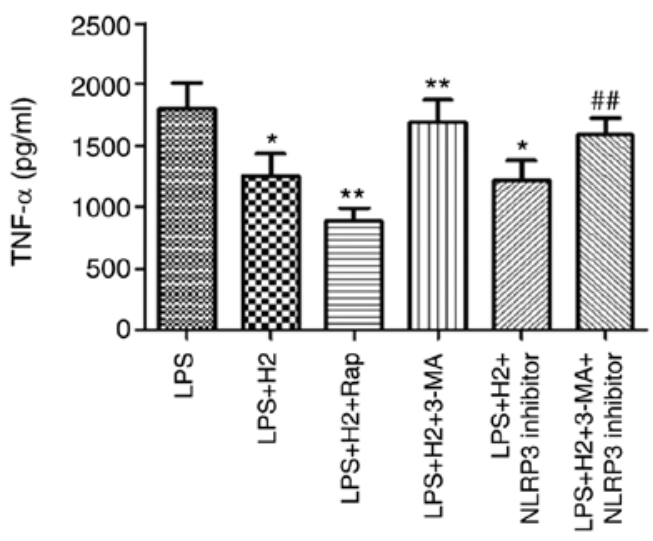

E

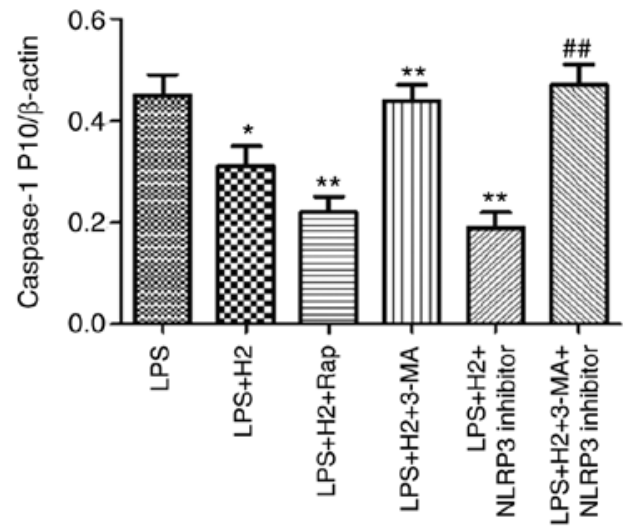

G

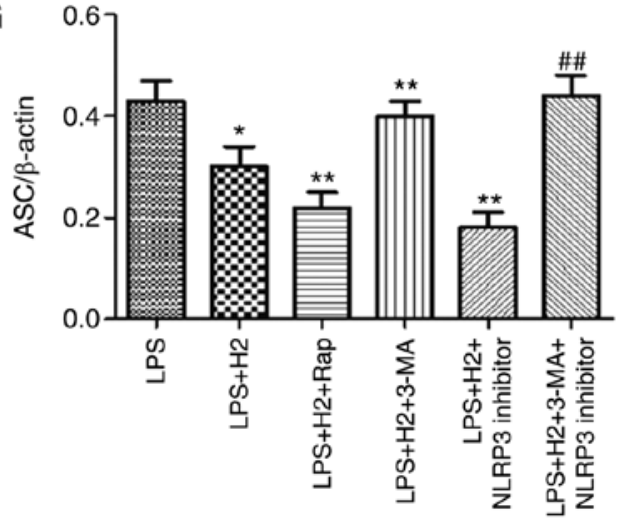

B

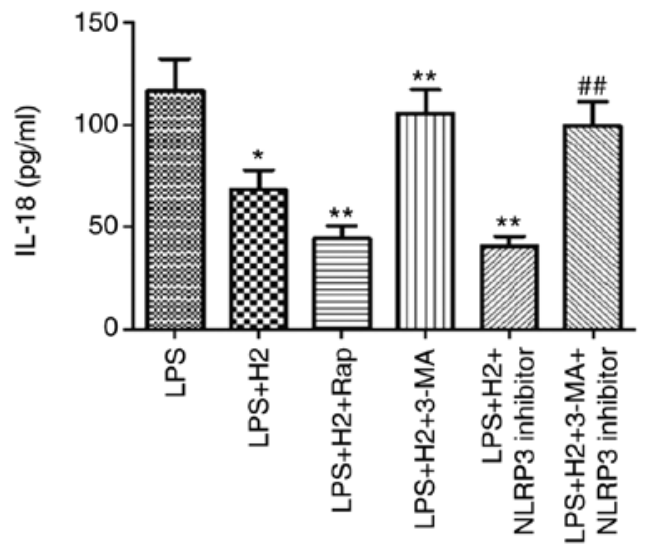

D
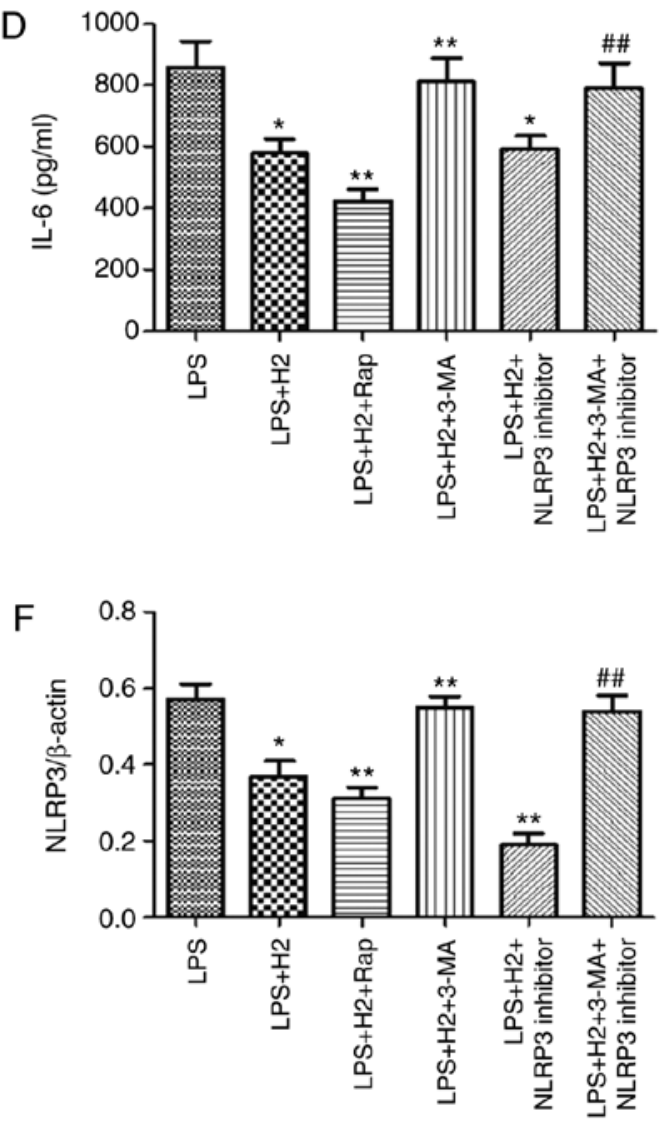

$\mathrm{H}$

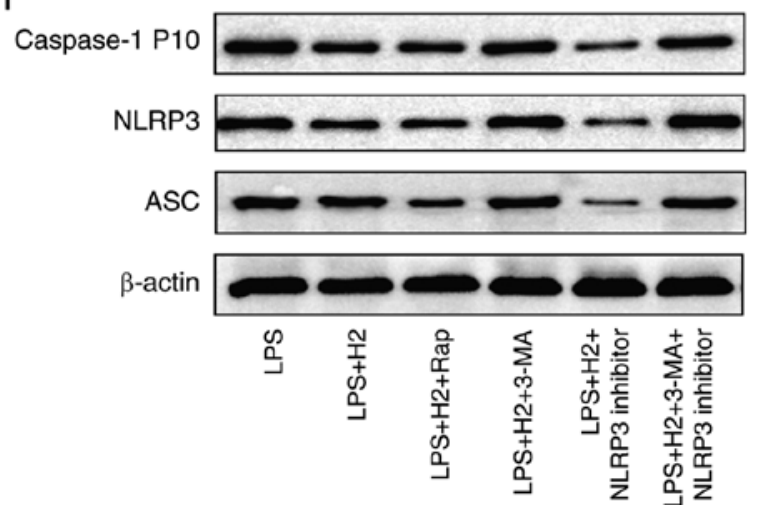

Figure 4. Effect of autophagy on inflammasome activation in macrophages induced by LPS and treated with $\mathrm{H}_{2}$. Macrophages were treated by LPS, ATP and $\mathrm{H}_{2}$, autophagy inducer Rap, and autophagy inhibitor 3-MA. The culture supernatants were collected to detect cytokines (A) IL-1 $\beta$, (B) IL-18, (C) TNF- $\alpha$ and (D) IL- 6 by ELISA, and cells were harvested to measure the expression of (E) caspase-1, (F) NLRP3 and (G) ASC by western blotting. (H) Representative blots of caspase-1, NLRP3 and ASC in cells. Data are expressed as the mean \pm standard deviation $(\mathrm{n}=6){ }^{*} \mathrm{P}<0.05$ vs. LPS group, ${ }^{* *} \mathrm{P}<0.05$ vs. LPS+H, group, $^{2}$ ${ }^{\# \#} \mathrm{P}<0.05$ vs. LPS $+\mathrm{H}_{2}+\mathrm{NLRP} 3$ inhibitor group. LPS, lipopolysaccharide; Rap, rapamycin; 3-MA, 3-methyladenine; IL, interleukin; TNF, tumor necrosis factor; NLRP3, NACHT, LRR and PYD domains-containing protein 3; ASC, apoptosis-associated speck-like protein containing a CARD; H $_{2}$, hydrogen. 


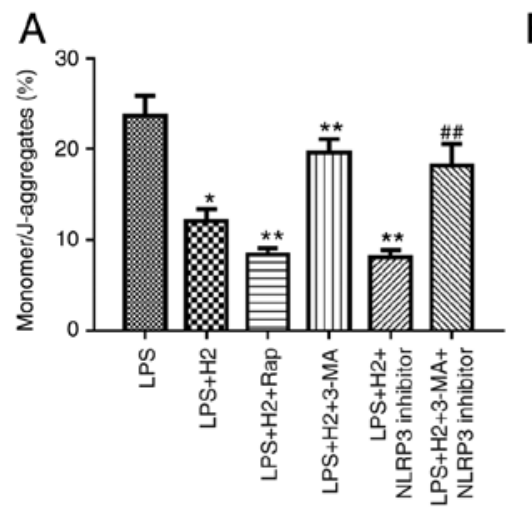

B
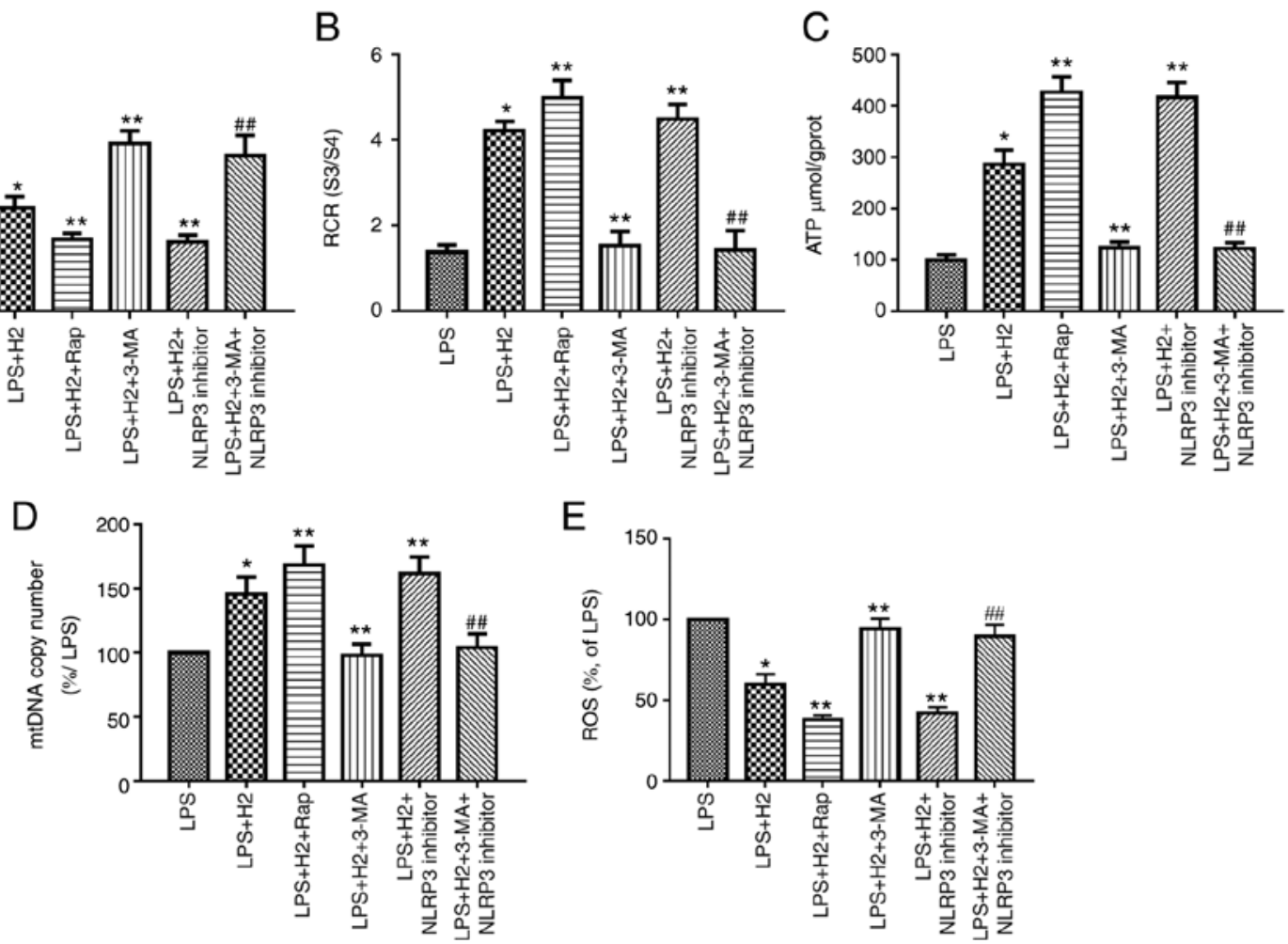

Figure $5 . \mathrm{H}_{2}$ alleviates mitochondrial dysfunction in macrophages induced by LPS via autophagy-mediated NLRP3 inactivation. Macrophages were treated with LPS, ATP and $\mathrm{H}_{2}$, autophagy inducer Rap and autophagy inhibitor 3-MA. Cells were harvested to measure (A) MMP, (B) RCR, (C) ATP, (D) mtDNA and (E) ROS release. Data are expressed as the mean \pm standard deviation $(n=6) .{ }^{*} \mathrm{P}<0.05$ vs. LPS group, ${ }^{* *} \mathrm{P}<0.05$ vs. LPS $+\mathrm{H}_{2}$ group, ${ }^{\# \#} \mathrm{P}<0.05 \mathrm{vs}$. LPS $+\mathrm{H}_{2}+\mathrm{NLRP} 3$ inhibitor group. LPS, lipopolysaccharide; Rap, rapamycin; 3-MA, 3-methyladenine; MMP, mitochondrial membrane potential; RCR, respiratory control ratio; mtDNA, mitochondrial DNA; ROS, reactive oxygen species; $\mathrm{H}_{2}$, hydrogen.

$\mathrm{P}<0.05)$. The autophagy inducer ameliorated liver and kidney injury in mice following $\mathrm{CLP}+\mathrm{H}_{2}$ treatment. 3-MA treatment reversed the beneficial effect of $\mathrm{H}_{2}$ on liver and kidney injury in the mice following $\mathrm{CLP}+\mathrm{H}_{2}$ treatment (Fig. 6A-D, $\mathrm{P}<0.05$ ).

These data suggest that $\mathrm{H}_{2}$ and the autophagy inducer Rap exerted a protective effect against acute lung, liver and kidney injury induced by CLP and that $\mathrm{H}_{2}$ improved the acute changes in the lung, liver and kidney induced via autophagy-mediated NLRP3 inflammasome inactivation in sepsis.

Lack of autophagy reverses the inhibitory effect of $\mathrm{H}_{2}$ on the NLRP3 inflammasome and cytokines in sepsis. To examine the role of autophagic proteins during NLRP3 inflammasome activation following $\mathrm{H}_{2}$ treatment in septic mice, the mice were treated with autophagy inducer and autophagy inhibitor. $\mathrm{H}_{2}$ and the autophagy inducer Rap attenuated the release of IL- $\beta$, IL-18, TNF- $\alpha$ and caspase-1 P10 and the expression of NLRP3 and ASC in the lungs of the septic mice. The autophagy inhibitor 3-MA exacerbated the release of IL-1 $\beta$, IL-18, TNF- $\alpha$ and caspase-1 P10 and the expression of NLRP3 and ASC in mice treated by CLP and $\mathrm{H}_{2}$ (Fig. 7A-F, $\mathrm{P}<0.05$ ). Consistent with the changes in the lungs of septic mice, the abnormal variation of cytokines and NLRP3 inflammasome exhibited the same trend in the liver (Fig. 8A-F, P<0.05) and kidney (Fig. 9A-F, P<0.05). These results indicate that autophagic activity increases and acts synergistically with $\mathrm{H}_{2}$ treatment to improve excessive cytokine release in septic mice. The lack of autophagy partly reversed the inhibitory effect of $\mathrm{H}_{2}$ on the NLRP3 inflammasome and cytokines in sepsis.

\section{Discussion}

Our previous and present research verified that $\mathrm{H}_{2}$ exerts a protective effect during sepsis; however, the mechanisms underlying the role of $\mathrm{H}_{2}$ in suppressing the pathological development of septic organ injury remain to be fully elucidated. Mitochondrial dysfunction and structural damage have been identified as key physiopathological factors in sepsis and are correlated with the severity of organ dysfunction and outcome of sepsis (24). Macrophages are the first line of defense against pathogens in sepsis (25). Macrophage mitochondrial dysfunction is involved in the pathogenesis of sepsis through several mechanisms, including systemic inflammatory responses, oxidative stress, energy metabolism and the intrinsic apoptotic pathway (26). It was previously reported that mitochondrial dysfunction induced by LPS is associated with mtDNA depletion and results in a lack of mitochondrial transcription $(27,28)$. Mitochondria are the main source of ROS, the production of which is a consequence of primary oxidative injury of mitochondrial respiratory complex proteins and mtDNA following exposure to LPS. The present study demonstrated that LPS and ATP treatment led to the accumulation of physiologically abnormal mitochondria and promoted mitochondrial dysfunction, as shown by the reduced MMP, mitochondrial RCR, ATP content and mtDNA copy number and increased ROS in macrophages. $\mathrm{H}_{2}$ alleviated the mitochondrial dysfunction in macrophages induced by LPS and ATP, and improved lung, liver and kidney injury. Therefore, $\mathrm{H}_{2}$ protected organ function in septic mice and enhanced the survival rate of sepsis. 

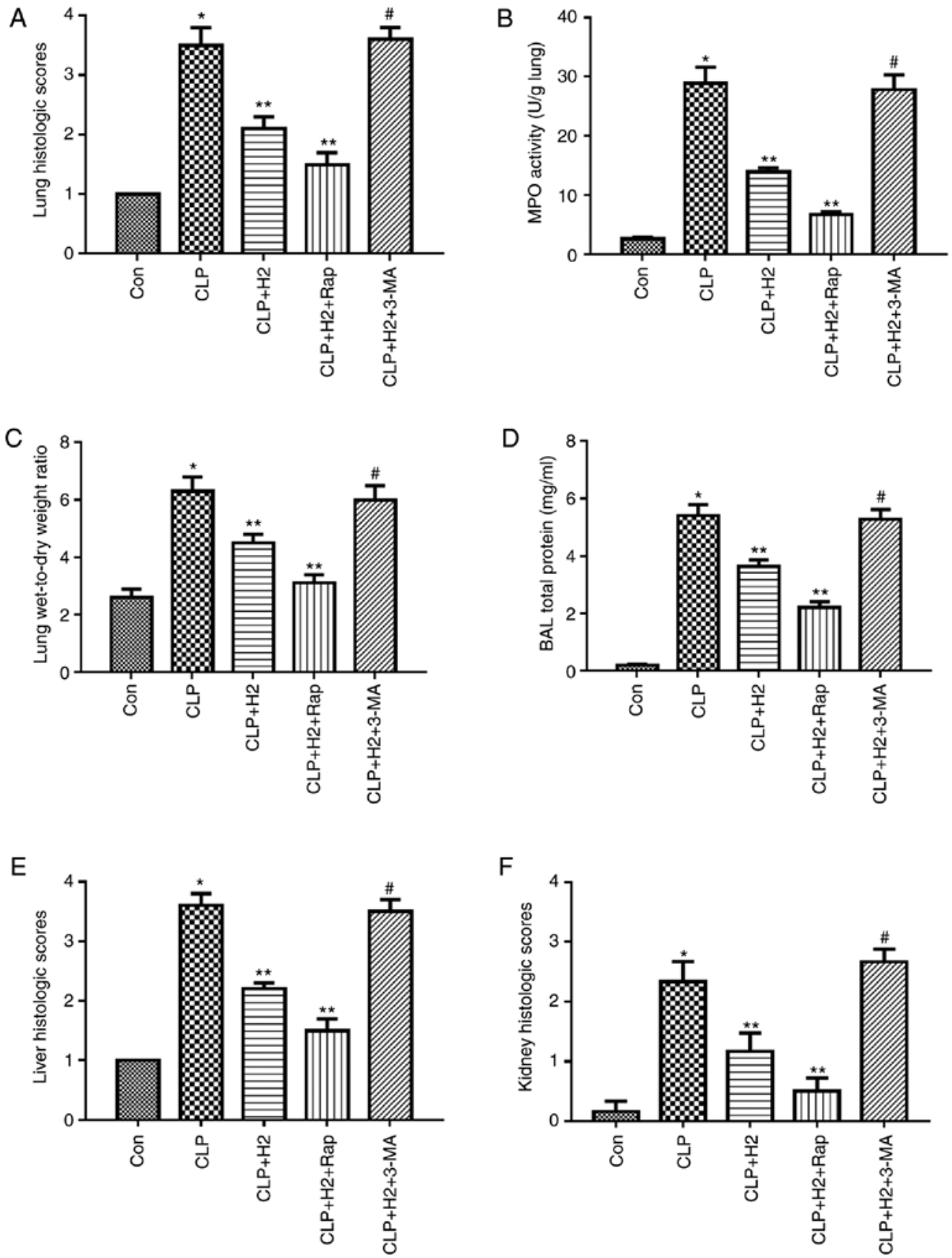

Figure 6. Effect of autophagy-mediated NACHT, LRR and PYD domains-containing protein 3 inactivation on lung injury, biochemical parameters of liver and kidney and survival rate in LPS-induced macrophages treated with $\mathrm{H}_{2}$. Sepsis was produced by CLP. Septic mice were treated with $\mathrm{H}_{2}$, autophagy inducer Rap and autophagy inhibitor 3-MA. After $24 \mathrm{~h}$, lung tissues were collected to detect (A) pathological tissue changes by hematoxylin and eosin staining, (B) MPO activity and (C) W/D weight ratio; (D) bronchoalveolar lavage fluid was collected to analyze total proteins. (E) Liver and (F) kidney tissues were collected to investigate pathological scores.

Accumulating evidence indicates that cellular damage induced by acute inflammatory responses leads to the progression of systemic inflammatory response syndrome. Macrophage activation contributes to the release of various pro-inflammatory cytokines, including IL-1 $\beta$, IL- 6 and TNF- $\alpha$, and leads to excessive ROS production, exacerbating the inflammatory cascade in sepsis. The inflammasome is a complex of cytoplasmic proteins formed in response to endogenous or exogenous pathogen-associated molecular patterns or danger-associated molecular patterns, which leads to an inflammatory response by modulating the cleavage and mature of pro-inflammatory cytokines, including pro-IL-1 $\beta$ and pro-IL18 (29). NLRP3, one of the most well-characterized inflammasomes, has been shown to be involved in conditions including sepsis and infectious diseases $(30,31)$. Excessive activation of the NLRP3 inflammasome is considered to be an important factor in the pathological development of septic injury (32). Once activated, NLRP3 recruits ASC and procaspase-1 to form a complex, which results in caspase-1 activation and the maturation of pro-inflammatory cytokines IL-1 $\beta$ and IL-18. Results reported by Wu et al (33), Ganz et al (34) and Li et al (35) indicate that activation of the NLRP3 inflammasome increases the expression of ASC in septic liver tissue. NLRP3 inflammasome activation and excessive cytokine 
G
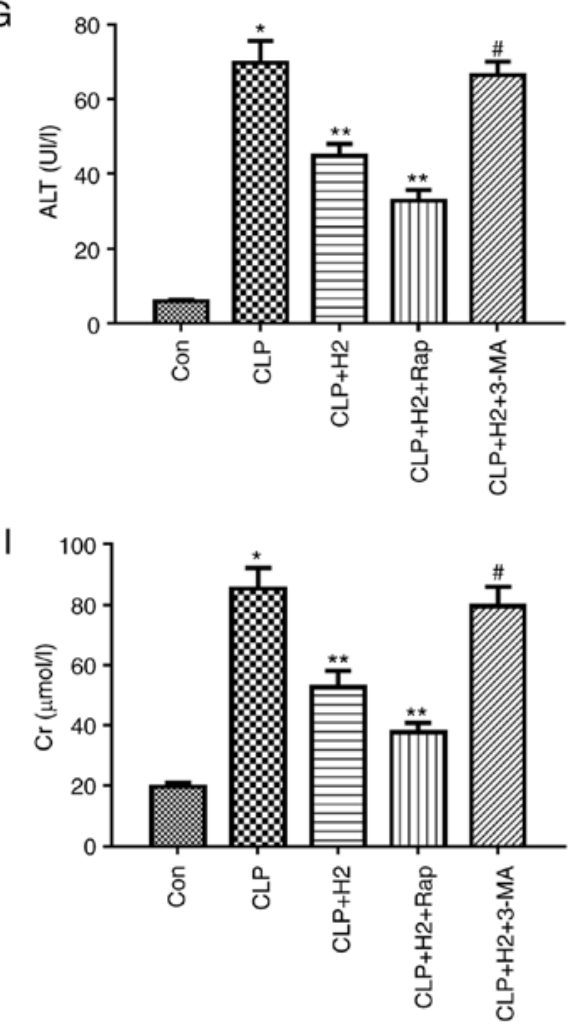

$\mathrm{H}$

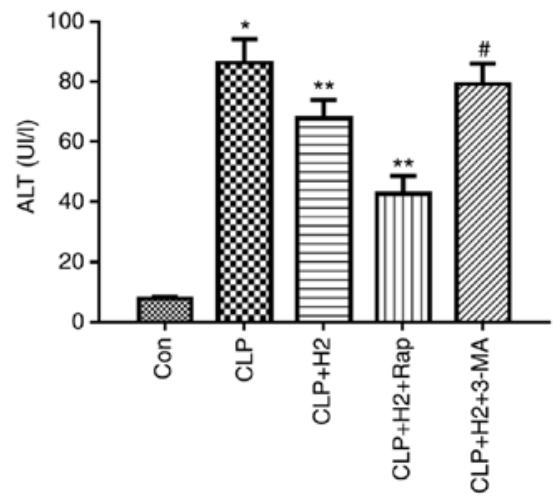

$\mathrm{J}$

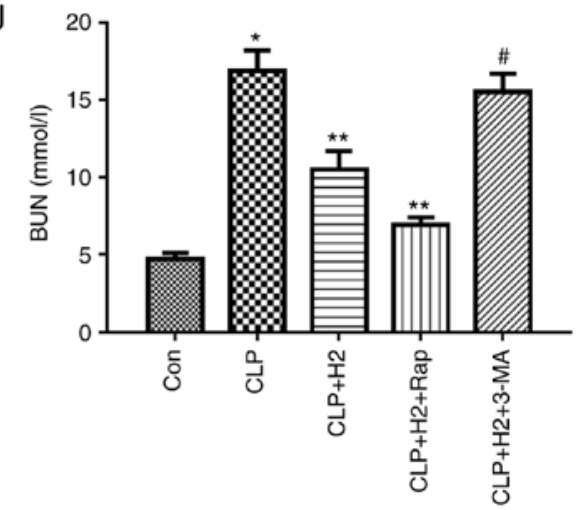

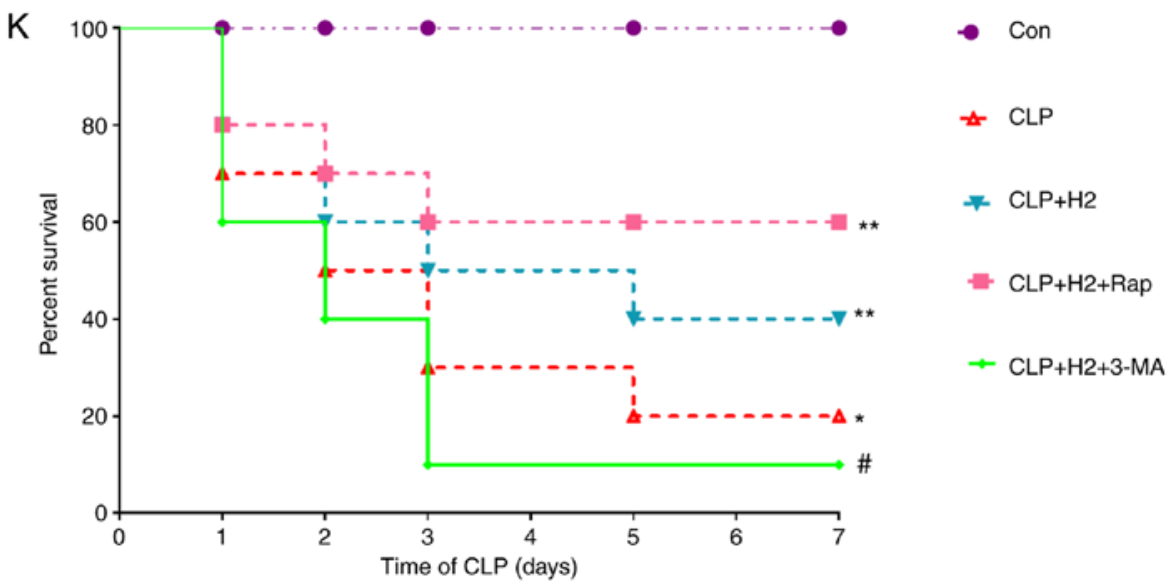

Figure 6. Continued. Blood was obtained to measure the biochemical parameters (G) ALT, (H) AST, (I) Cr and (J) BUN. (K) Survival rate was analyzed at 1 , 2, 3, 5 and 7 days post-CLP $(n=20)$. Data are expressed as the mean \pm standard deviation $(n=6) .{ }^{*} \mathrm{P}<0.05$ vs. Con group, ${ }^{* *} \mathrm{P}<0.05$ vs. CLP group, ${ }^{*} \mathrm{P}<0.05$ vs. $\mathrm{CLP}+\mathrm{H}_{2}$ group. LPS, lipopolysaccharide; CLP, cecal ligation and puncture; Rap, rapamycin; 3-MA, 3-methyladenine; MPO, myeloperoxidase, W/D, wet/dry; ALT, alanine transaminase; AST, aspartate transaminase; BUN, blood urea nitrogen; $\mathrm{Cr}$, creatinine; $\mathrm{H}_{2}$, hydrogen; Con, control.

expression were also observed in LPS and ATP-induced macrophages. Consistent with the results of previous studies, LPS and ATP treatment contributed to inflammasome pathway activation in the present study, including the increased expression of NLRP 3 and caspase- 1 and the maturation of IL- $\beta$ and IL-18 in macrophages. The release of TNF- $\alpha$ and IL- 6 exhibited the same trend as IL- $\beta$ and IL-18 in macrophages stimulated by LPS and ATP. In addition, inflammasome activation in sepsis was detected in vivo. The findings were consistent with the changes of macrophages in vitro: The NLRP3 inflammasome, ASC and procaspase-1 were markedly increased, with excessive release of cytokines IL-1 $\beta$, IL-18, TNF- $\alpha$ and IL-6. In line with our previous findings, $\mathrm{H}_{2}$ improved organ damage via alleviating the excessive release of pro-inflammatory cytokines. Furthermore, $\mathrm{H}_{2}$ inactivated the inflammasome via reducing the expression of NLRP3 and procaspase- 1 in macrophages induced by LPS and ATP, and in the lung, kidney and liver of septic mice. Whether $\mathrm{H}_{2}$ mitigated the inflammatory response via regulating the inflammasome activation was also investigated. The results demonstrated that $\mathrm{H}_{2}$ alleviated the inflammatory response and organ damage via inhibiting NLRP3 inflammasome pathway activation.

Autophagy is a self-degradation process for recycling organelles released by damaged cells. Under certain conditions, mitophagy selectively removes specific proteins and injured organelles, such as mitochondria (36). It has been 
A

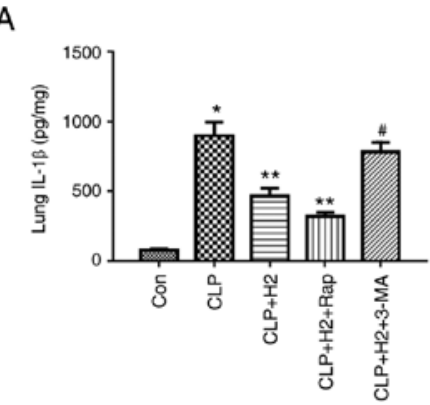

B

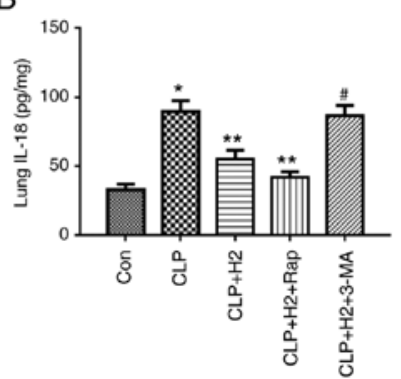

C

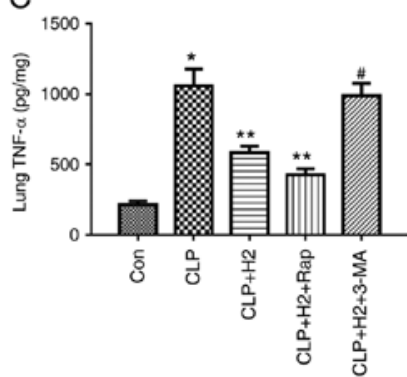

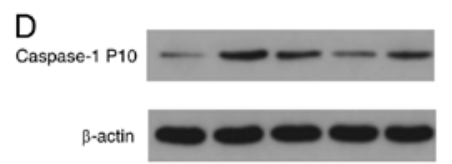

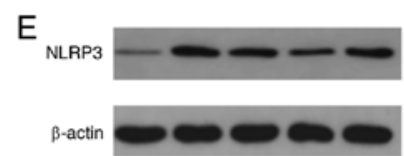

$\mathrm{F}$
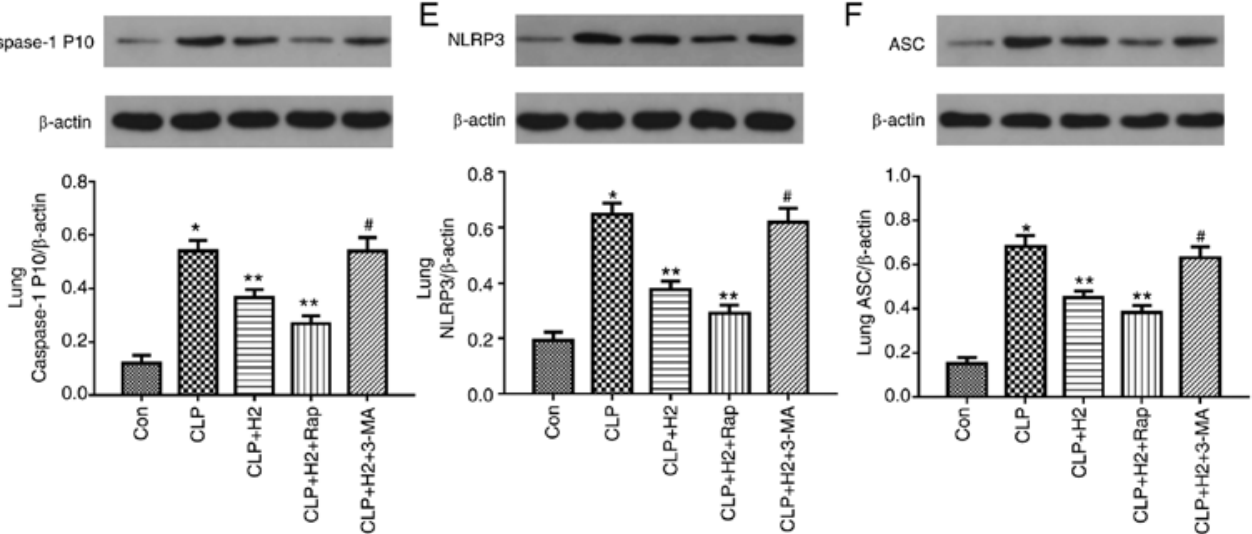

Figure 7. $\mathrm{H}_{2}$ alleviates cytokine release and NLRP3 inflammasome activation in the lungs of septic mice via increasing autophagy. Septic mice were treated with $\mathrm{H}_{2}$, autophagy inducer Rap and autophagy inhibitor 3-MA. After $24 \mathrm{~h}$, lung tissues were collected to detect cytokines (A) IL-1 13 , (B) IL-18 and (C) TNF- $\alpha$ by ELISA and the expression of (D) caspase-1, (E) NLRP3 and (F) ASC by western blotting. Data are expressed as the mean \pm standard deviation ( $\mathrm{n}=6$ ). ${ }^{*} \mathrm{P}<0.05$ vs. Con group, ${ }^{* *} \mathrm{P}<0.05$ vs. the CLP group, ${ }^{\prime} \mathrm{P}<0.05$ vs. $\mathrm{CLP}+\mathrm{H}_{2}$ group. Rap, rapamycin; 3-MA, 3-methyladenine; IL, interleukin; TNF, tumor necrosis factor; NLRP3, NACHT, LRR and PYD domains-containing protein 3; ASC, apoptosis-associated speck-like protein containing a CARD; CLP, cecal ligation and puncture; $\mathrm{H}_{2}$, hydrogen; Con, control.

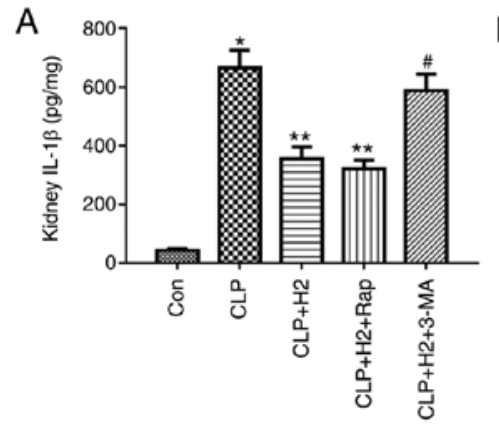

D
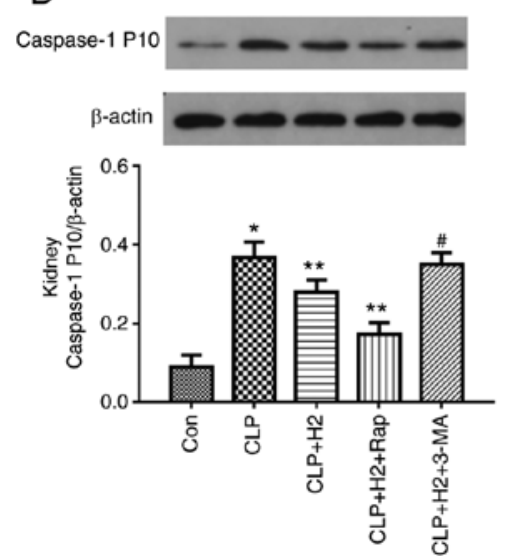

$B$

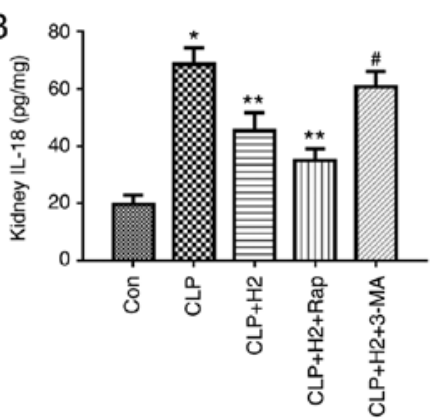

E
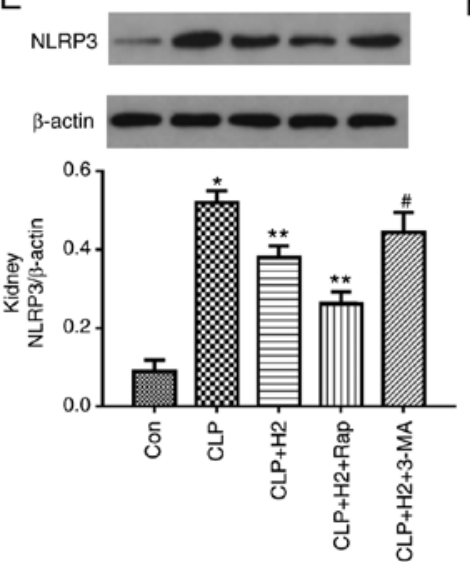

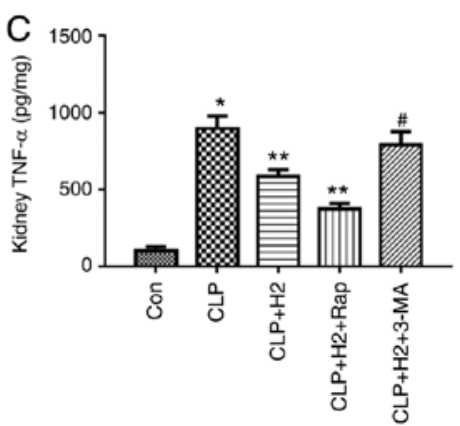

$\mathrm{F}$
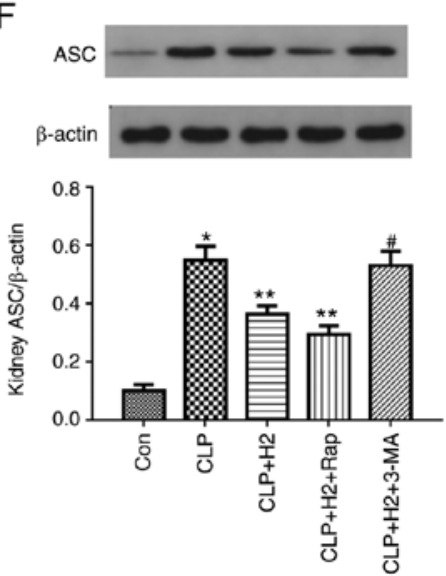

Figure 8. $\mathrm{H}_{2}$ alleviates cytokine release and NLRP3 inflammasome activation in the livers of septic mice via increasing autophagy. Septic mice were treated with $\mathrm{H}_{2}$, autophagy inducer Rap, and autophagy inhibitor 3-MA. After $24 \mathrm{~h}$, liver tissues were collected to detect cytokines (A) IL-1 $\beta$, (B) IL-18 and (C) TNF- $\alpha$ by ELISA and the expression of (D) caspase-1, (E) NLRP3 and (F) ASC by western blotting. Data are expressed as mean \pm standard deviation ( $\mathrm{n}=6$ ). ${ }^{*} \mathrm{P}<0.05$ vs. Con group, ${ }^{* *} \mathrm{P}<0.05$ vs. CLP group, ${ }^{~} \mathrm{P}<0.05$ vs. $\mathrm{CLP}+\mathrm{H}_{2}$ group. Rap, rapamycin; 3-MA, 3-methyladenine; IL, interleukin; TNF, tumor necrosis factor; NLRP3, NACHT, LRR and PYD domains-containing protein 3; ASC, apoptosis-associated speck-like protein containing a CARD; CLP, cecal ligation and puncture; $\mathrm{H}_{2}$, hydrogen; Con, control. 


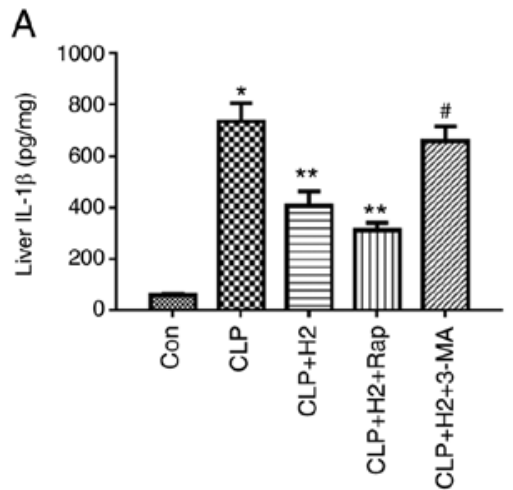

D

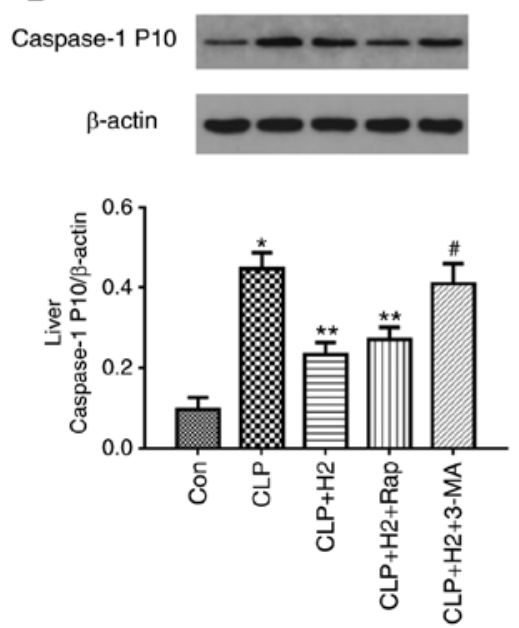

B

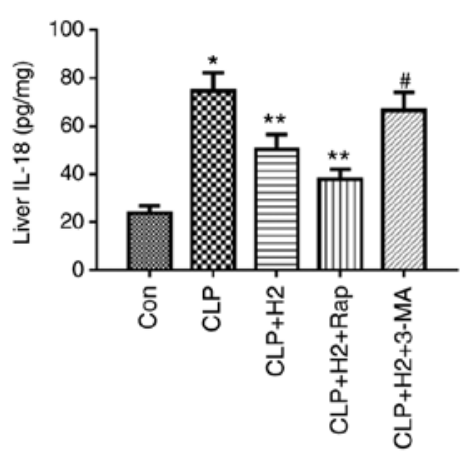

$E$
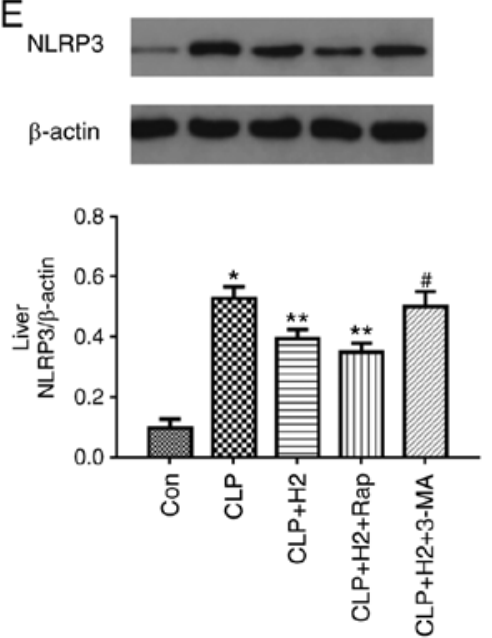
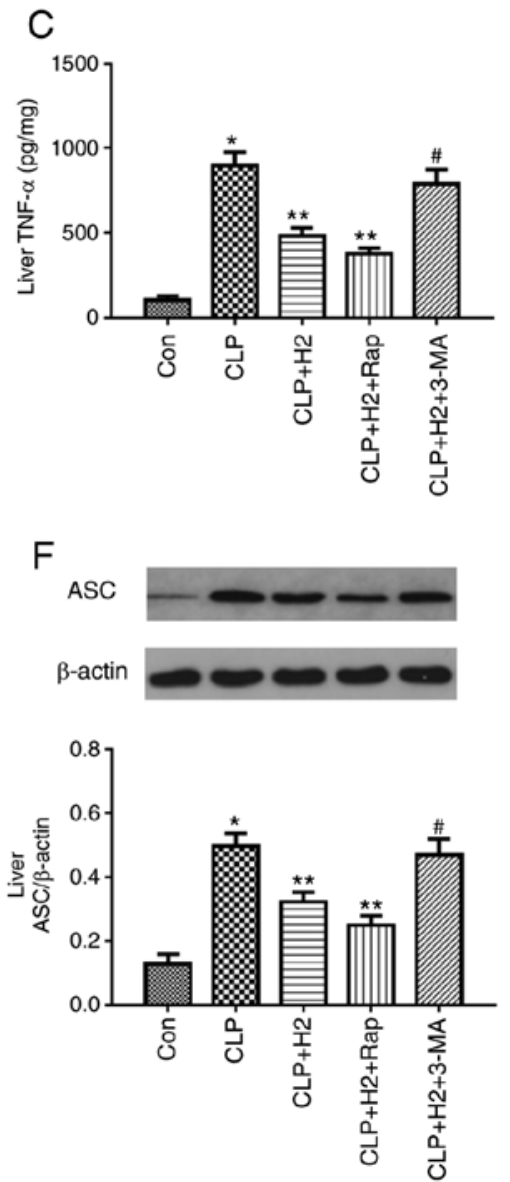

Figure 9. $\mathrm{H}_{2}$ alleviates cytokine release and NLRP3 inflammasome activation in the kidneys of septic mice via increasing autophagy. Septic mice were treated with $\mathrm{H}_{2}$, autophagy inducer Rap and autophagy inhibitor 3-MA. After $24 \mathrm{~h}$, kidney tissues were collected to detect cytokines (A) IL-1 $\beta$, (B) IL-18 and (C) TNF- $\alpha$ by ELISA and the expression of (D) caspase-1, (E) NLRP3 and (F) ASC by western blotting. Data are expressed as the mean \pm standard deviation $(\mathrm{n}=6)$. ${ }^{*} \mathrm{P}<0.05$ vs. Con group, ${ }^{* *} \mathrm{P}<0.05$ vs. CLP group, ${ }^{\#} \mathrm{P}<0.05$ vs. CLP+H ${ }_{2}$ group. Rap, rapamycin; 3-MA, 3-methyladenine; IL, interleukin; TNF, tumor necrosis factor; NLRP3, NACHT, LRR and PYD domains-containing protein 3; ASC, apoptosis-associated speck-like protein containing a CARD; CLP, cecal ligation and puncture; $\mathrm{H}_{2}$, hydrogen; Con, control.

reported that cardiac dysfunction and liver injury may be alleviated by the activation of autophagy in septic mice (37-39). Of note, it was reported that the activation of mitophagy was necessary to prevent organ injury in sepsis (40). LC3 and Beclin 1 are two key molecules involved in the initiation and progression of autophagy. LC3 is prone to the degradation of damaged mitochondria by binding p62 to the autophagosome (41). Nakahira et al reported that LPS and ATP treatment produced a greater abundance of swollen mitochondria with severely disrupted cristae in LC3B and Beclin 1-knockdown macrophages, and macrophages were prone to exhibit severe mitochondrial derangement and dysfunction following LPS and ATP treatment (13). The PINK1-Parkin pathway is part of the main mitophagic process (42). The lack of PINK1 and Parkin prevented the activation of mitophagy. In Pink1 and Parkin-knockout mice, sepsis was more likely to induce tissue injury, increasing mortality (43). The present study examined the activation and effect of autophagy on mitochondrial dysfunction, organ injury, organ function and survival rate following $\mathrm{H}_{2}$ treatment in vitro and in vivo. It was observed that the activation of autophagy, particularly mitophagy, was enhanced in macrophages induced by LPS and ATP, and that LC3I conversion to LC3II and the expression levels of Beclin 1, PINK1, Parkin and VDAC were increased in macrophages induced by LPS and ATP. $\mathrm{H}_{2}$ treatment increased PINK1/Parkin-mediated mitophagy via increasing the expression of LC3II, Beclin 1, PINK1, Parkin and VDAC in macrophages. The mechanisms of LPS inducing autophagy may be associated with mitochondrial damage, ROS generation and the excessive production of inflammatory cytokines, which promote autophagy under LPS stimulation (44); in addition, autophagy, as a protective mechanism, increases in stress conditions, such as LPS exposure. $\mathrm{H}_{2}$ exerts a protective effect during LPS challenge, which improves the autophagic process to inhibit mitochondrial damage, ROS generation and the excessive production of inflammatory cytokines.

Autophagy is closely associated with NLRP3 inflammasome activation. Autophagy acts to restore the balance of inflammatory responses, as uncontrolled and detrimental inflammation is inhibited via inflammasome inactivation and proinflammatory cytokine clearance (45). The lack of autophagy increased NLRP3 activation and the secretion of pro-inflammatory cytokines following LPS stimulation (46), whereas the induction of autophagy contributed to the degradation of NLRP3 and reduced the level of IL-1 $\beta$ (47). 
Mitophagy can recycle damaged mitochondria selectively, which activates the NLRP3 inflammasome (16). Furthermore, the immune cross-talk between autophagy and the inflammasome pathways in bacterial infection and sepsis have been investigated (48). The interplay between inflammasomes and autophagy varies markedly in sepsis and is affected by factors including pathogens, infection conditions, time duration, host cells and animal models (49). To further investigate the effect of autophagy and the inflammasome on $\mathrm{H}_{2}$ alleviating mitochondrial dysfunction and organ damage in sepsis, an autophagy inducer and inhibitor were used in the present study to examine the NLRP3 pathway, cytokines, organ dysfunction and damage indicators. As mentioned above, Rap attenuated NLRP3 activation, the expression of ASC, cleavage of caspase- 1 and the maturation of IL-1 $\beta$ and IL-18, and also improved mitochondrial dysfunction, tissue damage in the lung, liver and kidney, alleviated lung injury and liver and kidney dysfunction and improved survival rates in septic mice treated with $\mathrm{H}_{2}$. The autophagy inhibitor reversed the effect of inflammasome inactivation on these indicators in septic mice receiving $\mathrm{H}_{2}$ treatment. These results suggest that $\mathrm{H}_{2}$ alleviated the sepsis-induced mitochondrial dysfunction and inflammatory response via autophagy-mediated NLRP3 inflammasome inactivation.

In conclusion, the results of the present study demonstrate that $\mathrm{H}_{2}$ alleviated the mitochondrial dysfunction induced by LPS and ATP in macrophages and improved tissue injury in the lung, liver and kidney in septic mice. $\mathrm{H}_{2}$ was shown to exert a protective effect in sepsis via suppressing autophagy/mitophagy-mediated NLRP3 inflammasome activation under LPS stimulation or in an animal sepsis model. The contribution of autophagy and inflammasome inactivation to this protective process may uncover a mechanistic link between them when $\mathrm{H}_{2}$ is administered to protect against sepsis. However, the mechanisms underlying the role of $\mathrm{H}_{2}$ treatment in sepsis requires further investigation.

\section{Acknowledgements}

Not applicable.

\section{Funding}

This study was supported by grants from the National Natural Science Foundation of China (grant. nos. 81601667 to HC, 81671888 to $\mathrm{YY}, 81772043$ to $\mathrm{KX}$ and 81801889 to $\mathrm{YL}$ ) and the Natural Science Foundation of Tianjin City (grant. no. 18JCYBJC93700).

\section{Availability of data and materials}

The datasets used and/or analyzed during the present study are available from the corresponding author on reasonable request.

\section{Authors' contributions}

YY and KX designed the study and helped to edit and revise the manuscript; $\mathrm{HC}$ and XMa were involved in animal model establishment and sample collection, and drafted the manuscript; XMe, YW and YL were involved in the in vitro experiments; JF, LZ and YZ performed the detection of indicators. All authors read and approved the final manuscript.

\section{Ethics approval and consent to participate}

All experimental procedures were approved by the Institutional Animal Care and Use Committee of Tianjin Medical University and were performed in accordance with the National Institutes of Health Guide for Care and Use of Laboratory Animals. All efforts were made to minimize animal suffering and the number of animals used.

\section{Patient consent for publication}

Not applicable.

\section{Competing interests}

The authors declare that they have no competing interests.

\section{References}

1. van der Poll T, van de Veerdonk FL, Scicluna BP and Netea MG: The immunopathology of sepsis and potential therapeutic targets. Nat Rev Immunol 17: 407-420, 2017.

2. Dombrovskiy VY, Martin AA, Sunderram J and Paz HL: Rapid increase in hospitalization and mortality rates for severe sepsis in the United States: A trend analysis from 1993 to 2003. Crit Care Med 35: 1244-1250, 2007.

3. Dellinger RP, Levy MM, Rhodes A, Annane D, Gerlach H, Opal SM, Sevransky JE, Sprung CL, Douglas IS, Jaeschke R, et al: Surviving sepsis campaign: International guidelines for management of severe sepsis and septic shock, 2012. Intensive Care Med 39: 165-228, 2013.

4. Singer M, Deutschman CS, Seymour CW, Shankar-Hari M, Annane D, Bauer M, Bellomo R, Bernard GR, Chiche JD, Coopersmith CM, et al: The third international consensus definitions for sepsis and septic shock (Sepsis-3). JAMA 315: 801-810, 2016.

5. Wiersinga WJ, Leopold SJ, Cranendonk DR and van der Poll T: Host innate immune responses to sepsis. Virulence 5: 36-44, 2014.

6. Lamkanfi $\mathrm{M}$ and Dixit VM: Mechanisms and functions of inflammasomes. Cell 157: 1013-1022, 2014.

7. Rahim I, Djerdjouri B, Sayed RK, Fernández-Ortiz M, Fernández-Gil B, Hidalgo-Gutiérrez A, López LC, Escames G, Reiter RJ and Acuña-Castroviejo D: Melatonin administration to wild-type mice and nontreated NLRP3 mutant mice share similar inhibition of the inflammatory response during sepsis. J Pineal Res 63, 2017.

8. Feng Z, Qi S, Zhang Y, Qi Z, Yan L, Zhou J, He F, Li Q, Yang Y, Chen $\mathrm{Q}$, et al: Ly6G+ neutrophil-derived miR-223 inhibits the NLRP3 inflammasome in mitochondrial DAMP-induced acute lung injury. Cell Death Dis 8: e3170, 2017.

9. Liu Q, Ci X, Wen Z and Peng L: Diosmetin alleviates lipopolysaccharide-induced acute lung injury through activating the Nrf2 pathway and inhibiting the NLRP3 inflammasome. Biomol Ther (Seoul) 26: 157-166, 2018

10. Zhang Y, Li X, Grailer JJ, Wang N, Wang M, Yao J, Zhong R, Gao GF, Ward PA, Tan DX and Li X: Melatonin alleviates acute lung injury through inhibiting the NLRP3 inflammasome. J Pineal Res 60: 405-414, 2016.

11. Li P, Allen H, Banerjee S, Franklin S, Herzog L, Johnston C, McDowell J, Paskind M, Rodman L, Salfeld J, et al: Mice deficient in IL-1 beta-converting enzyme are defective in production of mature IL-1 beta and resistant to endotoxic shock. Cell 80: 401-411, 1995.

12. Sutterwala FS, Ogura Y, Szczepanik M, Lara-Tejero M, Lichtenberger GS, Grant EP, Bertin J, Coyle AJ, Galán JE, Askenase PW and Flavell RA: Critical role for NALP3/CIAS1/Cryopyrin in innate and adaptive immunity through its regulation of caspase-1. Immunity 24: 317-327, 2006. 
13. Nakahira K, Haspel JA, Rathinam VA, Lee SJ, Dolinay T, Lam HC, Englert JA, Rabinovitch M, Cernadas M, Kim HP, et al: Autophagy proteins regulate innate immune responses by inhibiting the release of mitochondrial DNA mediated by the NALP3 inflammasome. Nat Immunol 12: 222-230, 2011.

14. Zhang B, Wei W and Qiu J: ALK is required for NLRP3 inflammasome activation in macrophages. Biochem Biophys Res Commun 501: 246-252, 2018.

15. He C and Klionsky DJ: Regulation mechanisms and signaling pathways of autophagy. Annu Rev Genet 43: 67-93, 2009.

16. Kim MJ, Yoon JH and Ryu JH: Mitophagy: A balance regulator of NLRP3 inflammasome activation. BMB Rep 49: 529-535, 2016.

17. Shimada K, Crother TR, Karlin J, Dagvadorj J, Chiba N, Chen S, Ramanujan VK, Wolf AJ, Vergnes L, Ojcius DM, et al: Oxidized mitochondrial DNA activates the NLRP3 inflammasome during apoptosis. Immunity 36: 401-414, 2012.

18. Xie K, Yu Y, Pei Y, Hou L, Chen S, Xiong L and Wang G: Protective effects of hydrogen gas on murine polymicrobial sepsis via reducing oxidative stress and HMGB1 release. Shock 34: 90-97, 2010.

19. Dong A, Wang L, Wang YY, Bian YX, Yu YH and Xie KL: Role of autophagy in hydrogen-induced reduction of lung injury in septic mice. Chin J Anesthesiol 37: 632-636, 2017.

20. Chen HG, Xie KL, Han HZ, Wang WN, Liu DQ, Wang GL and Yu YH: Heme oxygenase-1 mediates the anti-inflammatory effect of molecular hydrogen in LPS-stimulated RAW 264.7 macrophages. Int J Surg 11: 1060-1066, 2013.

21. Livak KJ and Schmittgen TD: Analysis of relative gene expression data using real-time quantitative PCR and the 2(-Delta Delta C(T)) method. Methods 25: 402-408, 2001.

22. Iglesias-González J, Sánchez-Iglesias S, Beiras-Iglesias A, Soto-Otero R and Méndez-Álvarez E: A simple method for isolating rat brain mitochondria with high metabolic activity: Effects of EDTA and EGTA. J Neurosci Methods 213: 39-42, 2013.

23. Narendra DP, Jin SM, Tanaka A, Suen DF, Gautier CA, Shen J, Cookson MR and Youle RJ: PINK1 is selectively stabilized on impaired mitochondria to activate Parkin. PLoS Biol 8: e1000298, 2010

24. Azevedo LC: Mitochondrial dysfunction during sepsis. Endocr Metab Immune Disord Drug Targets 10: 214-223, 2010.

25. Mège JL, Mehraj V and Capo C: Macrophage polarization and bacterial infections. Curr Opin Infect Dis 24: 230-234, 2011.

26. Deng SY, Zhang LM, Ai YH, Pan PH, Zhao SP, Su XL, Wu DD, Tan HY, Zhang LN and Tsung A: Role of interferon regulatory factor-1 in lipopolysaccharide-induced mitochondrial damage and oxidative stress responses in macrophages. Int J Mol Med 40: 1261-1269, 2017

27. Yamada H, Arai T, Endo N, Yamashita K, Fukuda K, Sasada M and Uchiyama T: LPS-induced ROS generation and changes in glutathione level and their relation to the maturation of human monocyte-derived dendritic cells. Life Sci 78: 926-933, 2006.

28. Suliman HB, Welty-Wolf KE, Carraway M, Tatro L and Piantadosi CA: Lipopolysaccharide induces oxidative cardiac mitochondrial damage and biogenesis. Cardiovasc Res 64: 279-288, 2004.

29. Mariathasan S, Newton K, Monack DM, Vucic D, French DM, Lee WP, Roose-Girma M, Erickson S and Dixit VM: Differential activation of the inflammasome by caspase- 1 adaptors ASC and Ipaf. Nature 430: 213-218, 2004.

30. Reboldi A, Dang EV, McDonald JG, Liang G, Russell DW and Cyster JG: Inflammation. 25-Hydroxycholesterol suppresses interleukin-1-driven inflammation downstream of type I interferon. Science 345: 679-684, 2014

31. Wirnsberger G, Zwolanek F, Asaoka T, Kozieradzki I, Tortola L, Wimmer RA, Kavirayani A, Fresser F, Baier G, Langdon WY, et al: Inhibition of CBLB protects from lethal Candida albicans sepsis. Nat Med 22: 915-923, 2016.

32. Hao H, Cao L, Jiang C, Che Y, Zhang S, Takahashi S, Wang G and Gonzalez FJ: Farnesoid X receptor regulation of the NLRP3 inflammasome underlies cholestasis-associated sepsis. Cell Metab 25: 856-867.e5, 2017.
33. Wu Y, Ren J, Zhou B, Ding C, Chen J, Wang G, Gu G, Wu X, Liu S, Hu D and Li J: Gene silencing of non-obese diabetic receptor family (NLRP3) protects against the sepsis-induced hyper-bile acidaemia in a rat model. Clin Exp Immunol 179: 277-293, 2015.

34. Ganz M, Csak T, Nath B and Szabo G: Lipopolysaccharide induces and activates the Nalp3 inflammasome in the liver. World J Gastroenterol 17: 4772-4778, 2011.

35. Li S, Wu H, Han D, Ma S, Fan W, Wang Y, Zhang R, Fan M, Huang Y, Fu X and Cao F: A novel mechanism of mesenchymal stromal cell-mediated protection against sepsis: Restricting inflammasome activation in macrophages by increasing mitophagy and decreasing mitochondrial ROS. Oxid Med Cell Longev 2018: 3537609. 2018.

36. Saito T and Sadoshima J: Molecular mechanisms of mitochondrial autophagy/mitophagy in the heart. Circ Res 116: 1477-1490, 2015.

37. Hsieh CH, Pai PY, Hsueh HW, Yuan SS and Hsieh YC: Complete induction of autophagy is essential for cardioprotection in sepsis. Ann Surg 253: 1190-1200, 2011.

38. Yen YT, Yang HR, Lo HC, Hsieh YC, Tsai SC, Hong CW and Hsieh $\mathrm{CH}$ : Enhancing autophagy with activated protein $\mathrm{C}$ and rapamycin protects against sepsis-induced acute lung injury. Surgery 153: 689-698, 2013.

39. Lin CW, Lo S, Perng DS, Wu DB, Lee PH, Chang YF, Kuo PL, Yu ML, Yuan SS and Hsieh YC: Complete activation of autophagic process attenuates liver injury and improves survival in septic mice. Shock 41: 241-249, 2014.

40. Carchman E and Zuckerbraun B: Mitophagy/mitochondrial biogenesis is necessary to prevent organ injury in sepsis and is dependent on TLR9 signaling. J Am Coll Surg 213 (Suppl): S59, 2011.

41. Lazarou M: Keeping the immune system in check: A role for mitophagy. Immunol Cell Biol 93: 3-10, 2015.

42. Vives-Bauza C, Zhou C, Huang Y, Cui M, de Vries RL, Kim J, May J, Tocilescu MA, Liu W, Ko HS, et al: PINK1-dependent recruitment of Parkin to mitochondria in mitophagy. Proc Natl Acad Sci USA 107: 378-383, 2010.

43. Kang R, Zeng L, Xie Y, Yan Z, Zhou B, Cao L, Klionsky DJ, Tracey KJ, Li J, Wang H, et al: A novel PINK1- and PARK2-dependent protective neuroimmune pathway in lethal sepsis. Autophagy 12: 2374-2385, 2016.

44. Zhang D, Zhou J, Ye LC, Li J, Wu Z, Li Y and Li C: Autophagy maintains the integrity of endothelial barrier in LPS-induced lung injury. J Cell Physiol 233: 688-698, 2018.

45. Cadwell K: Crosstalk between autophagy and inflammatory signalling pathways: Balancing defence and homeostasis. Nat Rev Immunol 16: 661-675, 2016.

46. Yin JJ, Xie G, Zhang N and Li Y: Inhibiting autophagy promotes endoplasmic reticulum stress and the ROS-induced nod-like receptor 3-dependent proinflammatory response in HepG2 cells. Mol Med Rep 14: 3999-4007, 2016.

47. Giegerich AK, Kuchler L, Sha LK, Knape T, Heide H, Wittig I, Behrends C, Brüne B and von Knethen A: Autophagy-dependent PELI3 degradation inhibits proinflammatory IL1B expression. Autophagy 10: 1937-1952, 2014.

48. Suzuki T, Franchi L, Toma C, Ashida H, Ogawa M, Yoshikawa Y, Mimuro H, Inohara N, Sasakawa C and Nuñez G: Differential regulation of caspase-1 activation, pyroptosis, and autophagy via Ipaf and ASC in Shigella-infected macrophages. PLoS Pathog 3: e111, 2007.

49. Pu Q, Gan C, Li R, Li Y, Tan S, Li X, Wei Y, Lan L, Deng X, Liang H, et al: Atg7 deficiency intensifies inflammasome activation and pyroptosis in pseudomonas sepsis. J Immunol 198: 3205-3213, 2017

This work is licensed under a Creative Commons Attribution-NonCommercial-NoDerivatives 4.0 International (CC BY-NC-ND 4.0) License. 